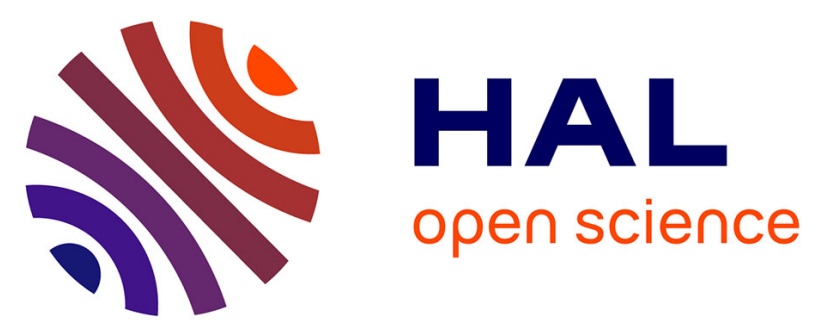

\title{
Mechanical behavior at high temperatures of highly oxygen- or hydrogen-enriched $\alpha$ and (Prior-) $\beta$ phases of zirconium alloys
}

\author{
Isabelle Turque, Raphaël Chosson, Matthieu Le Saux, Jean-Christophe \\ Brachet, Valérie Vandenberghe, Jérôme Crépin, Anne-Françoise \\ Gourgues-Lorenzon
}

\section{To cite this version:}

Isabelle Turque, Raphaël Chosson, Matthieu Le Saux, Jean-Christophe Brachet, Valérie Vandenberghe, et al.. Mechanical behavior at high temperatures of highly oxygen- or hydrogen-enriched $\alpha$ and (Prior-) $\beta$ phases of zirconium alloys. 18th International symposium on zirconium in the nuclear industry, May 2016, Hilton Head Island, SC, United States. pp.240-280, 10.1520/STP159720160063. hal-01702107

\section{HAL Id: hal-01702107}

https://hal-mines-paristech.archives-ouvertes.fr/hal-01702107

Submitted on 6 Feb 2018

HAL is a multi-disciplinary open access archive for the deposit and dissemination of scientific research documents, whether they are published or not. The documents may come from teaching and research institutions in France or abroad, or from public or private research centers.
L'archive ouverte pluridisciplinaire HAL, est destinée au dépôt et à la diffusion de documents scientifiques de niveau recherche, publiés ou non, émanant des établissements d'enseignement et de recherche français ou étrangers, des laboratoires publics ou privés. 
This is a preprint of an article accepted for publication in Zirconium in the Nuclear Industry: 18th International Symposium, STP 1597, ASTM International, West Conshohocken, PA, Www.astm.org

\author{
I. Turque ${ }^{1,2}$, R. Chosson ${ }^{1,2,3}$, M. Le Saux ${ }^{1}$, J.C. Brachet ${ }^{1}$, V. Vandenberghe ${ }^{1,4}$, J. Crépin $^{2}$, and \\ A.F. Gourgues-Lorenzon ${ }^{2}$
}

\title{
Mechanical behavior at high temperature of highly oxygen- or hydrogen-enriched $\alpha$ and (prior-) $\beta$ phases of zirconium alloys
}

\begin{abstract}
During a hypothetical loss-of-coolant accident (LOCA), zirconium alloy fuel claddings can be loaded by internal pressure and exposed to steam at high temperature (HT, potentially up to $1200^{\circ} \mathrm{C}$ ), then cooled and water quenched. A significant fraction of the oxygen reacting with the cladding during HT oxidation diffuses beneath the oxide through the metallic substrate. This induces a progressive transformation of the metallic $\beta$ Zr phase layer into an intermediate layer of $\alpha_{\mathrm{Zr}}(\mathrm{O})$ phase containing up to $7 \mathrm{wt} . \%$ of oxygen. Furthermore, in some specific conditions, the cladding may rapidly absorb a significant amount of hydrogen during

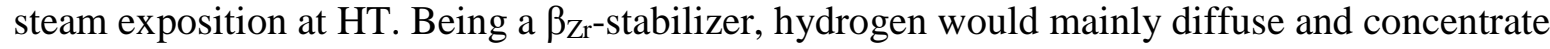
up to several thousands of wt.ppm into the inner $\beta_{\mathrm{Zr}}$ phase layer.

Oxygen and hydrogen are known to modify the metallurgical and mechanical properties of zirconium alloys but data are scarce for high contents, especially at HT. However, such data are important basic components to improve the assessment of the oxidized cladding mechanical behavior and integrity during and after LOCA-like thermal-mechanical transients.

This study intended to provide new, more comprehensive data on the HT mechanical behavior of the $\alpha_{\mathrm{Zr}}(\mathrm{O})$ and the (prior-) $\beta_{\mathrm{Zr}}$ phases containing high contents of oxygen and hydrogen, respectively. Model samples, produced from M5 $\AA^{5}$ and Zircaloy-4 cladding tubes, homogeneously charged in oxygen $(\leq 6 \mathrm{wt} . \%)$ and in hydrogen $(\leq 3000 \mathrm{wt} . \mathrm{ppm})$ respectively, were prepared. Their mechanical behavior was determined under vacuum between 800 and $1100^{\circ} \mathrm{C}$ for the oxygen-enriched $\alpha z$ phase, and in air between 700 and $20^{\circ} \mathrm{C}$, after cooling from the $\beta \mathrm{Zr}$ temperature domain, for the hydrogen-enriched (prior-) $\beta_{\mathrm{Zr}}$ phase. The $\alpha \mathrm{Zr}$ phase is substantially strengthened and embrittled by oxygen. Power-law and nearly linear creep regimes are observed and were modelled for stress levels beyond and below $15 \mathrm{MPa}$, respectively. The model $\alpha_{\mathrm{Zr}}(\mathrm{O})$ material experiences a ductile-to-brittle transition at $1000-1100^{\circ} \mathrm{C}$ for oxygen contents between 3.4 and $4.3 \mathrm{wt}$.\%. The viscoplastic behavior of the $\alpha \mathrm{Zr}(\mathrm{O})$ phase was used to evaluate the contribution of the $\alpha \mathrm{Zr}(\mathrm{O})$ layer to the HT creep behavior of an oxidized fuel cladding tube subjected to internal pressure. The model (prior-) $\beta_{\text {Zr }}$ phase becomes macroscopically brittle at temperatures $\leq 135^{\circ} \mathrm{C}$ and $\leq 350-400^{\circ} \mathrm{C}$ for average hydrogen contents
\end{abstract}

\footnotetext{
${ }^{1}$ DEN-Service de Recherches Métallurgiques Appliquées (SRMA), CEA, Université Paris-Saclay, F-91191 Gif-surYvette, France, e-mail: matthieu.lesaux@cea.fr (corresponding author)

${ }^{2}$ MINES ParisTech, PSL Research University, Centre des Matériaux, CNRS UMR 7633, BP 87, 91003 Evry cedex, France

${ }^{3}$ Now at AREVA NP, 69456 Lyon Cedex 06, France

${ }^{4}$ Now at DEN-Service d'Etudes Mécaniques et Thermiques (SEMT), CEA, Université Paris-Saclay, F-91191 Gifsur-Yvette, France

${ }^{5} \mathrm{M} 5$ is a registered trademark of AREVA NP in the USA or other countries
} 
of 2000 wt.ppm and 3000 wt.ppm, respectively. The effect of hydrogen on ductility decreases with increasing temperature and vanishes beyond $500^{\circ} \mathrm{C}$. In the ductile domain, the (prior-) $\beta_{\mathrm{Zr}}$ phase containing 1700 3200 wt.ppm of hydrogen has a higher flow stress than the hydrogen-free material at $500^{\circ} \mathrm{C}$, and a lower one at $700^{\circ} \mathrm{C}$, respectively. Young's modulus and plastic isotropy of the (prior-) $\beta$ zr phase are not significantly modified by high hydrogen contents.

Keywords: Zircaloy-4, M5®, oxygen, hydrogen, LOCA, mechanical behavior, high temperature

\section{Introduction}

During a loss of coolant accident (LOCA) hypothetical scenario in a light water reactor, fuel claddings made of zirconium alloys are loaded by internal pressure and exposed to steam at high temperature (HT, up to $1200^{\circ} \mathrm{C}$ ) before being cooled, then water quenched. At HT, a significant fraction of the oxygen reacting at the metal/oxide interface diffuses through the metallic substrate. Once the solubility limit of oxygen in the $\beta$ zr phase is reached, a metallic layer of oxygen-stabilized $\alpha_{\mathrm{Zr}}$ phase, called $\alpha_{\mathrm{Zr}}(\mathrm{O})$, grows from the interface between the oxide layer and the $\beta_{\mathrm{Zr}}$ phase substrate [1][2][3]. There is a strong through-thickness gradient in oxygen concentration, from $\sim 7 \mathrm{wt} . \%$ at the oxide $/ \alpha \mathrm{Zr}(\mathrm{O})$ interface down to $2 \mathrm{wt} . \%$ at the $\alpha \mathrm{Zr}(\mathrm{O}) / \beta_{\mathrm{Zr}}$ interface and not higher than $0.6 \mathrm{wt} . \%$ in the $\beta_{\mathrm{Zr}}$ phase. During cooling, the $\beta_{\mathrm{Zr}}$ phase layer transforms back into $\alpha_{\mathrm{Zr}}$ and forms the so-called prior- $\beta_{\mathrm{Zr}}$ phase, with a typical Widmanstätten or parallel-lath structure morphology [4].

The cladding subjected to internal pressure at HT may swell and burst at the beginning of the LOCA transient. The quenching at the end of the transient induces internal stresses, due to e.g. inhomogeneity in thermal expansion coefficients and phase transformations. These internal stresses, potentially associated with additional mechanical loading, can result in a brittle failure of the cladding once it is heavily oxidized and hydrided. When analyzing the mechanical behavior of the cladding at HT, and then during and after quenching, the effects of both oxygen and hydrogen should be taken into account.

On the one hand, the mechanical response of the cladding during a LOCA-like transient depends on its degree of oxidation. In particular, the $\alpha_{\mathrm{Zr}}(\mathrm{O})$ phase layer formed at HT can have strengthening and embrittling effects [3][5][6]. A good knowledge of the mechanical properties of this phase at HT is thus an important issue. However, most of open literature data were obtained for oxygen contents lower than $2 \mathrm{wt} . \%$ [7][8][9][10][11][12][13] or did not concern the viscoplastic behavior at HT [7][14]. There seems to be no data about the creep behavior of the $\alpha \mathrm{Zr}(\mathrm{O})$ phase for oxygen contents higher than $2 \mathrm{wt} . \%$. A ductile-to-brittle transition appears as a function of the oxygen content but this transition is known neither for HT nor for oxygen contents higher than 2 wt. $\%$.

On the second hand, during in-service operation, a fraction of the hydrogen released during corrosion by the primary water environment is absorbed by the cladding. The end-of-life hydrogen content expected for high burn-up cladding is $~ 600$ wt.ppm for Zircaloy-4 [15] and 100 wt.ppm for M5® [16]. A significant hydrogen uptake can also occur in some specific conditions during steam exposition at HT, e.g., during post-breakaway oxidation at temperatures typically lower than $1050^{\circ} \mathrm{C}$. However, for modern nuclear fuel cladding alloys such as low-tin 
Zircaloy-4 and M5®, breakaway oxidation occurs too late [17][18][19][20] to affect the cladding behavior during a LOCA transient.

"Semi-integral" LOCA tests have been performed on single fuel rods [21][22][23] or on a bundle of rods [24] to simulate the whole LOCA transient. They have shown that fast and substantial secondary hydriding can occur during HT steam exposure following the ballooning and burst sequence: local hydrogen concentrations up to 3000-4000 wt.ppm were measured in the vicinity of burst opening after only a few tens of seconds under steam at HT. In that case, secondary hydriding results from the oxidation of the cladding inner surface after steam has penetrated through the burst crack into the gap between the fuel pellets and the inner cladding surface. Then, local hydrogen uptake is induced by the resultant increase in hydrogen partial pressure inside that gap when moving away from the burst opening, due to steam starved conditions [25][26]. The resulting hydrogen distribution within the cladding tube is heterogeneous [27]. Hydrogen mainly concentrates into the inner $\beta$ Zr phase layer [3][28][29]. The mechanical behavior of the cladding during and after quenching further depends on the properties of that (prior-) $\beta$ Zr phase layer, which is the only ductile part of the oxidized cladding once cooled down after a LOCA transient [2][3][22].

During or after quenching, the burst cladding might fail in two different manners, depending on the characteristics of the transient and resulting cladding microstructure and geometry. At the burst location, the cladding is thinnest and its oxidation level is highest; a few centimeters away from the burst location, the cladding is thicker and less oxidized but more heavily hydrided [24][30]. Several studies addressed the effect of hydrogen on the resistance to quenching [23] and the post-quench mechanical properties [3][22][31][32] of zirconium alloys fuel claddings oxidized at HT. It was shown that the effect of hydrogen results from an intrinsic embrittlement mechanism [3] but also from an increase, in the presence of hydrogen, in solubility limit of oxygen in the $\beta_{\mathrm{Zr}}$ phase [33][34][35], leading to higher oxygen content and additional embrittlement [1][2][3][14][18]. However, most of these studies focused on hydrogen contents lower than 1000 wt.ppm, as the main purpose was to investigate the effect of pre-transient inservice hydriding. To the authors' knowledge, data for alloys with higher hydrogen contents and cooled from HT (two-phase $\left(\alpha_{\mathrm{Zr}}+\beta_{\mathrm{Zr}}\right)$ and single-phase $\beta_{\mathrm{Zr}}$ domains) are very scarce and limited to room temperature [31][36], while a significant effect of temperature is expected.

This work aims at improving both experimental databases and understanding of the separate effects of high oxygen and high hydrogen contents on the behavior of microstructures having experienced a thermal cycle up to HT. The first part of the present paper addresses HT (800$1000^{\circ} \mathrm{C}$ ) viscoplastic flow and fracture of the $\alpha_{\mathrm{Zr}}(\mathrm{O})$ phase containing more than $2 \mathrm{wt} . \%$ of oxygen. A part of the results has already been reported elsewhere [37]. A model is developed on the basis of these data to describe the viscoplastic behavior of the $\alpha \mathrm{zr}(\mathrm{O})$ phase. This model is then used with finite element analysis to evaluate the effect of the $\alpha_{\mathrm{Zr}}(\mathrm{O})$ phase layer on the creep behavior of a fuel cladding tube subjected to an internal pressure at HT. The second part of the study focusses on the mechanical behavior of the (prior-) $\beta_{\mathrm{Zr}}$ phase between 700 and $20^{\circ} \mathrm{C}$, during cooling from HT, and on the effect of high hydrogen contents. The effects of oxygen on the properties of the (prior-) $\beta$ Zr phase are not directly addressed in this paper and will be published elsewhere. 


\section{Mechanical behavior of highly oxygen-enriched $\alpha \mathrm{Zr}(0)$ phase}

\section{Materials and experimental procedures}

Sample preparation-Model oxygen-enriched $\alpha_{\mathrm{Zr}}$ phase samples were prepared from fully recrystallized M5® cladding tubes from AREVA NP (nominal outer diameter $\sim 9.5 \mathrm{~mm}$, wall thickness $\sim 0.57 \mathrm{~mm}$, chemical composition reported in Table 1). Oxygen charging was performed in several steps. First, the tube samples were oxidized in steam at $1100^{\circ} \mathrm{C}$ in the EDGAR facility [38] in order to introduce oxygen into the material, mainly under the form of outer zirconia and intermediate $\alpha_{\mathrm{Zr}}(\mathrm{O})$ phase layers. Oxidation durations at $1100^{\circ} \mathrm{C}$ were set from the targeted oxygen contents by using available oxidation kinetics [3][18][20][33][39]. 265-mmlong oxidized samples were then annealed under secondary vacuum for $3 \mathrm{~h}$ at $1200^{\circ} \mathrm{C}$ in order to homogenize the oxygen concentration (by reduction of the oxide and diffusion of oxygen across the wall thickness). Model $\alpha_{\mathrm{Zr}}$ phase samples with about 2 (10), 3.2 (16), 4.3 (20) and 5.8 (26) wt.\% (at.\%) oxygen contents were thus prepared, covering the typical range of contents reported for the $\alpha \mathrm{zr}(\mathrm{O})$ phase. Homogeneity and mean oxygen contents were measured by Electron Probe Micro Analysis (EPMA, CAMECA ${ }^{6}$ SX100 microprobe) with a typical accuracy of $0.25 \mathrm{wt} . \%$.

TABLE 1-Nominal chemical composition (in wt.\%) of the studied materials in their as-received state.

\begin{tabular}{cccccccc}
\hline Material & $\mathrm{Sn}$ & $\mathrm{Fe}$ & $\mathrm{Cr}$ & $\mathrm{Nb}$ & $\mathrm{O}$ & $\mathrm{Zr}$ & $\mathrm{H}$ \\
\hline M5 & - & 0.04 & - & 1.0 & 0.14 & Bal. & $<0.0005$ \\
Zircaloy-4 & 1.3 & 0.2 & 0.1 & - & 0.13 & Bal. & $<0.0005$ \\
\hline
\end{tabular}

Mechanical testing - In order to avoid handling of such brittle samples at room temperature [14] the annealing step was carried out just before creep testing, in an electrical-mechanical tensile machine with a radiation furnace, operated under secondary vacuum [40][41]. The temperature was monitored using Pt/Pt-Rh thermocouples spot-welded onto the specimen surface.

After the homogenization step, the temperature was decreased (by a few ${ }^{\circ} \mathrm{C} / \mathrm{s}$ ) down to the selected creep test temperature. The specimens were axially loaded in tension. The gauge part was delimited by using two alumina rings cement-pasted onto the tube. The axial temperature gradient along the gauge region was $10 \pm 5^{\circ} \mathrm{C}$. The axial elongation was continuously measured by using a laser extensometer with a spatial resolution of $1 \mu \mathrm{m}$.

Creep tests were performed at constant temperature between 800 and $1000^{\circ} \mathrm{C}$ for true axial stresses ranging from 2 to $31 \mathrm{MPa}$. As in [40], several constant load levels were successively applied to each specimen. Indeed, no or very limited primary creep was observed at the beginning of every loading step. A steady-state true strain rate was thus determined for each load level. A test with increasing, then decreasing load levels evidenced no significant loading history effect on the observed creep behavior.

\footnotetext{
${ }^{6}$ CAMECA is a registered trademark of CAMECA SAS in the USA or other countries
} 
Microstructure of the model materials-After creep tests, the specimens were cut at midgauge length, perpendicular to the tensile axis for metallographic observation. Their microstructure was mainly composed of $\alpha_{\mathrm{Zr}}(\mathrm{O})$ grains (Fig. 1), enriched in oxygen and depleted in niobium and iron (Fig. 2). Regions of untransformed $\beta_{\mathrm{Zr}}$ (or prior- $\beta_{\mathrm{Zr}}$ ) phase, strongly enriched in niobium (up to $8 \mathrm{wt} . \%$ ) and iron, and containing $0.5 \pm 0.2 \mathrm{wt} . \%$ of oxygen, were also found locally (Fig. 2(a)). The volume fraction of these regions was very low $(<10 \%)$ for the lowest test temperatures or the highest mean oxygen contents. It reached $10-15 \%$ for tests beyond $1000^{\circ} \mathrm{C}$ for the material containing $2 \mathrm{wt} . \%$ oxygen, in agreement with thermodynamic equilibrium estimated using the Thermo-Calc ${ }^{\mathrm{TM}}{ }^{7}$ software together with the Zircobase database [42] (Fig. 3). Thus, some $\beta_{\mathrm{Zr}}$ phase was still present during the HT creep tests. Outside these regions, the oxygen content was satisfactorily homogeneous across the wall thickness (Fig. 2), with the exception of the sample with $5.8 \mathrm{wt} . \%$ of oxygen (gradient of $\sim 2 \mathrm{wt} . \%$ ).

The grain morphology of the tested specimens depended on the mean oxygen content (Fig. 1). In the material containing $\sim 2 \mathrm{wt} . \%$ of oxygen, the $\alpha_{\mathrm{Zr}}(\mathrm{O})$ phase appeared as coarse lamellae, 100 200- $\mu \mathrm{m}$-long and 20 40- $\mu \mathrm{m}$-thick, mainly oriented perpendicular to the cladding axis. Lamellae were separated by a continuous network of residual niobium-enriched prior- $\beta_{\text {Zr }}$ phase and/or metastable $\beta_{\mathrm{Zr}}$ phase already known in $\mathrm{Zr}-\mathrm{Nb}$ alloys [43]. For higher oxygen contents, $\alpha \mathrm{Zr}(\mathrm{O})$ grains were larger $(200 \sim 500 \mu \mathrm{m})$, more equiaxed and the residual (prior-) $\beta_{\mathrm{Zr}}$ phase was not continuous. $\alpha \mathrm{zr}(\mathrm{O})$ grains were smaller at the cladding surfaces. In the material containing $5.8 \mathrm{wt} . \%$ of oxygen, a thin residual oxide layer was found at the outer surface and underlying $\alpha_{\mathrm{Zr}}(\mathrm{O})$ grains were partially columnar. Indeed, at such high oxygen content, the material was nearly saturated in oxygen (solubility limit $\sim 7 \mathrm{wt} . \%$ ) and the concentration gradient and the driving force were low, so that longer soaking durations would have been necessary to fully homogenize the material.

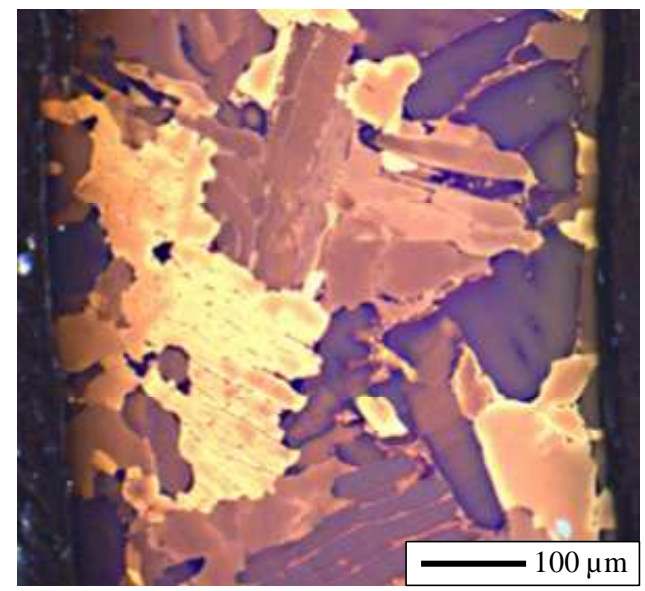

(a)

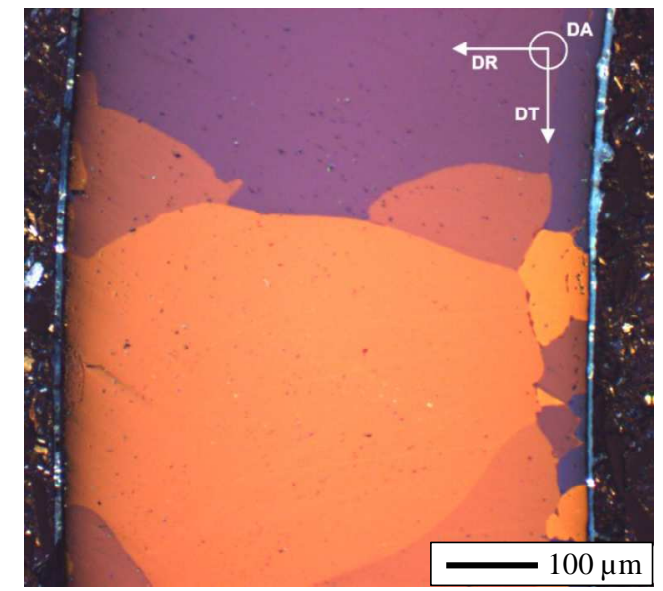

(b)

FIG. 1-Optical micrographs of transverse cross-sections of creep tested model $\alpha_{\mathrm{Zr}}(\mathrm{O})$ samples containing in average (a) 2 wt.\% and (b) 4.3 wt.\% of oxygen (outer surface on the left); DR: radial direction; DA: tube axis; DT: circumferential direction.

\footnotetext{
${ }^{7}$ Thermo-Calc is a trademark of Thermo-Calc Software
} 


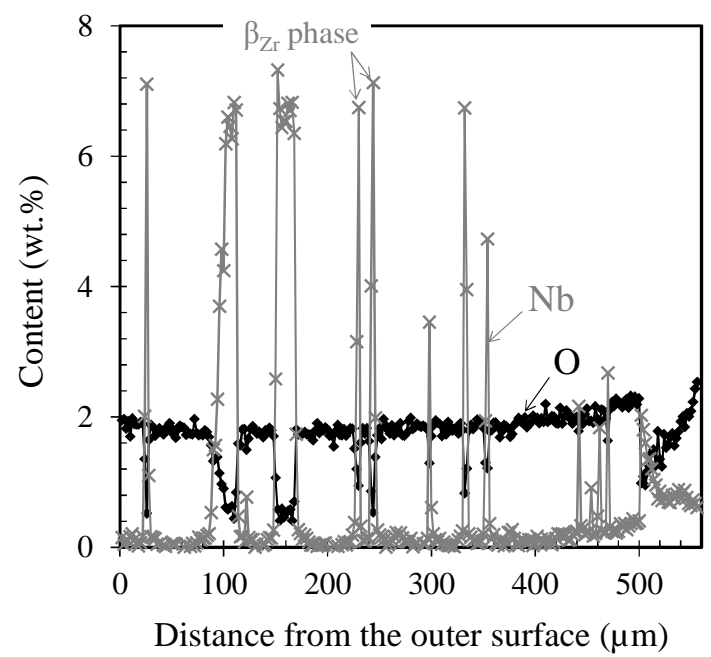

(a)

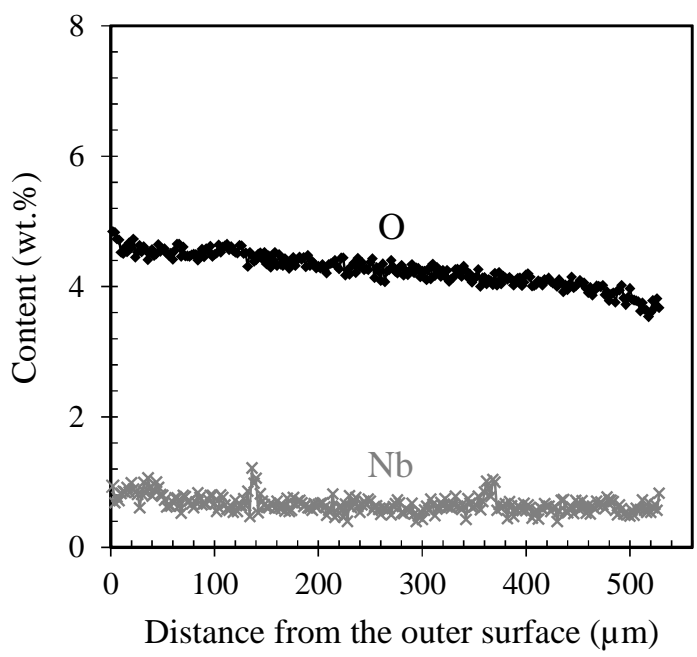

(b)

FIG. 2-Oxygen and niobium concentration profiles (EPMA) across the thickness of model $\alpha_{Z r}(O)$ samples containing in average (a) $2 \mathrm{wt}$ \% and (b) $4.3 \mathrm{wt} \%$ of oxygen.

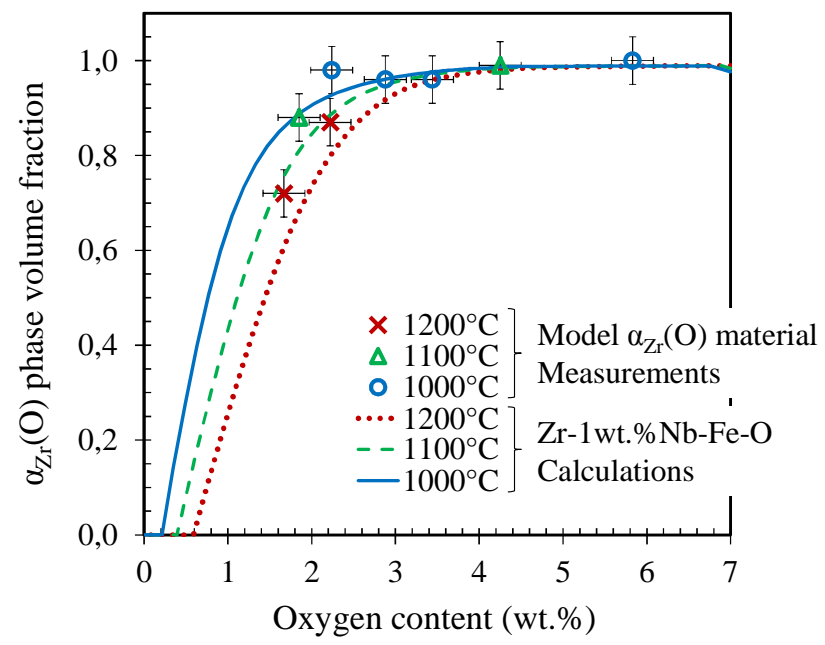

FIG. 3-Measured (EPMA) and calculated (Thermo-Calc ${ }^{\mathrm{TM}}+$ Zircobase) $\alpha_{\mathrm{Zr}}(\mathrm{O})$ phase volume fraction as a function of oxygen content and temperature.

The crystallographic texture of the model $\alpha_{\mathrm{Zr}}(\mathrm{O})$ material containing $\sim 2 \mathrm{wt} . \%$ of oxygen was investigated by electron backscatter diffraction (EBSD) on $\sim 500$ grains and by neutron diffraction (Léon Brillouin Laboratory, CEA Saclay) on $\sim 10^{6}$ grains, respectively. Both measurements showed a strong texture with $\langle c\rangle$ axes mainly perpendicular to the tube axis (Fig. 4). No preferential orientation of the $\langle c\rangle$ axes along the radial or hoop directions was evidenced using EBSD. Kearns factors values (i.e. fraction of resolved basal poles aligned along a particular macroscopic direction) of 0.41 and $0.44 \pm 0.05$ were respectively determined along the tube axial and hoop directions. These values are similar to those ( 0.36 and 0.51 , respectively) 
measured by EBSD on a $\alpha \mathrm{Zr}(\mathrm{O})$ layer formed during oxidation in steam at $1100^{\circ} \mathrm{C}$ on a specimen of the as-received material.

From these results, it was considered that the model $\alpha_{\mathrm{Zr}}(\mathrm{O})$ material, prepared by oxidation, dissolution and homogenization, was reasonably representative of the $\alpha_{\mathrm{Zr}}(\mathrm{O})$ layer observed in claddings oxidized at HT [44].
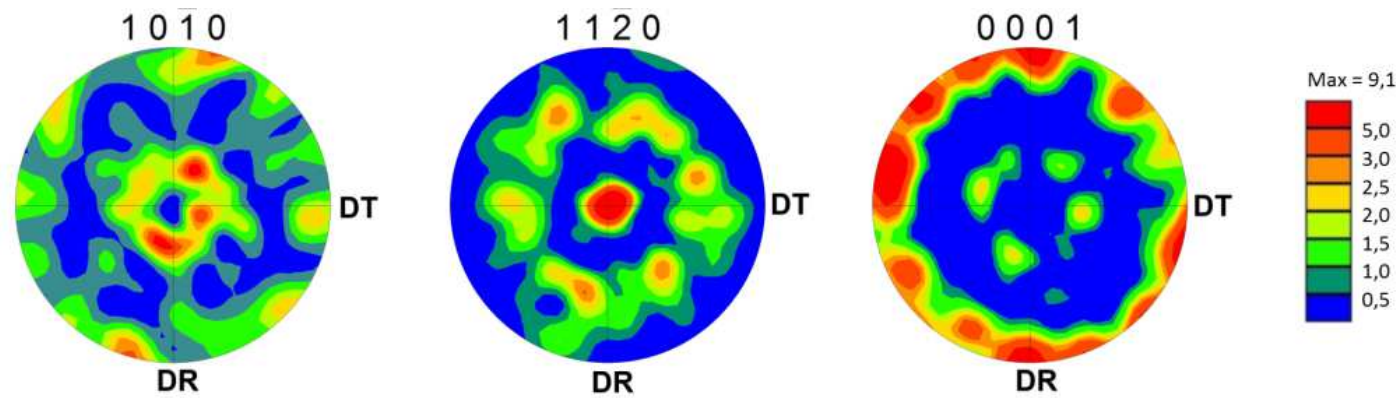

(a)
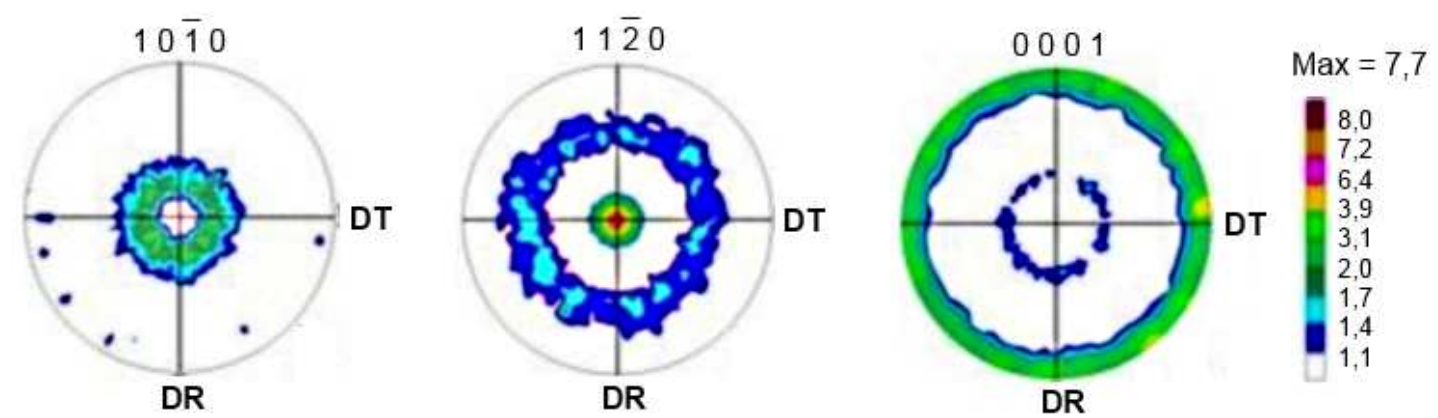

(b)

FIG. $4-\{10.0\},\{11.0\}$ and $\{00.1\}$ pole figures recalculated for a model $\alpha_{Z r}(O)$ sample containing 2 wt. $\%$ of oxygen in average: (a) surface analysis by EBSD, $(b)$ volume analysis by neutron diffraction; DR: radial direction; DT: circumferential direction.

\section{Viscoplastic behavior of the model materials}

Viscoplastic flow-Specimens containing more than $4 \mathrm{wt}$ \% oxygen failed in a brittle manner without significant strain. The steady-state viscoplastic flow behavior of model $\alpha_{\mathrm{Zr}}(\mathrm{O})$ samples containing up to $3.4 \mathrm{wt}$ \% oxygen is shown in Fig. 5. Two creep regimes were observed. Whatever the creep test temperature, for stresses higher than $15 \mathrm{MPa}$, the strain rate follows a power-law dependence upon stress with a stress exponent, $n$, close to 5 . For lower stresses $(\leq 10 \mathrm{MPa})$, a nearly linear flow regime takes place at 900,1000 and $1100^{\circ} \mathrm{C}$.

The high-stress power-law regime, probably controlled by dislocation glide and climb, was already reported for zirconium alloys, enriched in oxygen or not [10][12][40]. In non-enriched $\alpha_{\mathrm{Zr}}$, the linear creep regime was associated with a Coble-type diffusional flow along grain boundaries [47]. Here, the grain size in the oxygen-enriched material was significantly larger $\left(\sim 6.75 \cdot 10^{5} \mu \mathrm{m}^{3}\right)$ than that of a non-enriched material in the $\alpha_{\mathrm{Zr}}$ domain $\left(\sim 10^{3} \mu \mathrm{m}^{3}\right)$. The linear creep regime may thus rely on another flow mechanism that could not be clearly identified on the 
basis of available data. Nevertheless, a qualitative analysis, taking oxygen partition and grain size into account [44], was made in order to evaluate contributions from the Nabarro-Herring (bulk diffusional flow) [48], Coble and Harper-Dorn (viscous glide) [49] deformation regimes. This analysis suggested that diffusional flow dominates in spite of the relatively large grain size. The influence of grain size on viscoplastic flow of the model $\alpha_{\mathrm{Zr}}(\mathrm{O})$ microstructure has still to be experimentally determined to further investigate this point.

As reported in [37], the oxygen-enriched $\alpha_{\mathrm{Zr}}(\mathrm{O})$ material has a significantly higher creep resistance than the as-received, non-enriched material. The ratio between strain rates of $\alpha \mathrm{Zr}$ (extrapolated from [40]) to that of $\alpha_{\mathrm{Zr}}(\mathrm{O})$ is between 100 and 1000. For a given stress level, the strain rate of $\alpha_{\mathrm{Zr}}(\mathrm{O})$ containing $2 \mathrm{wt} . \%$ oxygen is $10^{4}$ times lower than that of $\beta_{\mathrm{Zr} \text {. Oxygen- }}$ induced strengthening increases with oxygen content, strain rates being reduced by nearly a factor 10 when the oxygen content is increased from 2 up to $3.2 \mathrm{wt} . \%$.

By considering the present results for model oxygen-enriched $\alpha_{\mathrm{Zr}}(\mathrm{O})$ phase (fabricated from $\mathrm{M} 5 \circledR)$ together with the data reported in [40] for non-enriched $\mathrm{Zr}-1 \mathrm{wt} . \% \mathrm{Nb}-0.14 \mathrm{wt} . \% \mathrm{O}$, the viscoplastic strain rate of $\mathrm{Zr}-1 \mathrm{wt} . \% \mathrm{Nb}$ and its dependence on the oxygen content could be fairly well described by the following phenomenological equation, already used by [10], [11], and [12]:

$$
\dot{\varepsilon}=\frac{A}{T} \exp \left(-\frac{Q}{R T}\right) \sigma^{n} \exp \left(-B C_{O}\right)
$$

In Eq. (1), $\dot{\varepsilon}$ is the true strain rate, $\sigma$ is the true stress in MPa, $T$ is the temperature in $\mathrm{K}, C_{O}$ is the oxygen content in wt.\%, $R$ is the gas constant; $A, Q, n$ and $B$ are material parameters; their adjusted values are given in Table 2 for each creep regime. The values of activation energy $Q$ are comparable to those reported for non-oxygen enriched $\alpha \mathrm{Zr}$ phase in $\mathrm{Zr}-1 \mathrm{wt} . \% \mathrm{Nb}-$ $0.14 \mathrm{wt} . \% \mathrm{O}$ [40]. The effect of oxygen is weaker in the linear regime than in the power-law regime. As illustrated in Fig. 5, the model accurately reproduces the viscoplastic behavior of the model $\alpha \mathrm{Zr}(\mathrm{O})$ material.

TABLE 2-Model parameters adjusted to describe each viscoplastic flow regime of the model oxygen-enriched $\alpha_{Z r}$ material.

\begin{tabular}{ccccc}
\hline $\begin{array}{c}\text { Deformation } \\
\text { regime }\end{array}$ & $A\left(\mathrm{~K} . \mathrm{MPa}^{-\mathrm{n}} \cdot \mathrm{s}^{-1}\right)$ & $n$ & $Q\left(\mathrm{~kJ}^{\mathrm{m}} \mathrm{mol}^{-1}\right)$ & $B\left(\mathrm{wt} . \%{ }^{-1}\right)$ \\
\hline Linear & $5.75 \cdot 10^{3}$ & 1 & 180 & 0.53 \\
Power-law & $4.80 \cdot 10^{3}$ & 5 & 222 & 2.29 \\
\hline
\end{tabular}




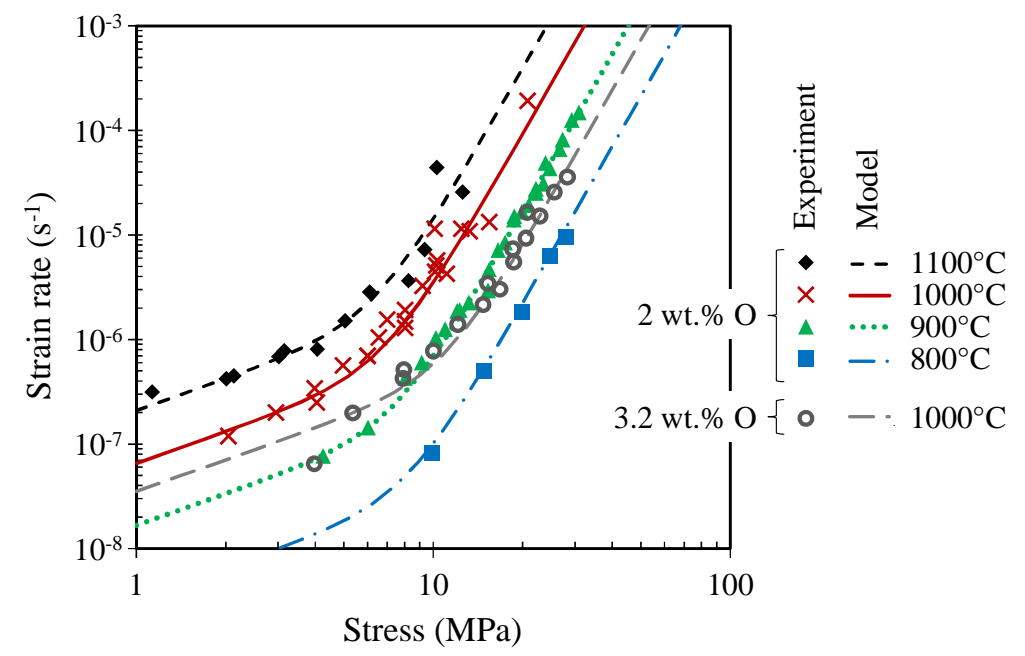

FIG. 5-True tensile strain rate vs true tensile stress: experimental data on model $\alpha_{\mathrm{Zr}}(O)$ samples (symbols) and predictions from Eq. 1 (lines). For the sake of simplicity, samples containing 2.9 3.4 wt.\% of oxygen are labelled "3.2 wt.\% O".

Predictions from Eq. (1) are compared in Fig. 6 to those from literature models, at $1000^{\circ} \mathrm{C}$ for stress levels of 2 and $20 \mathrm{MPa}$, relevant to the linear and power-law creep regimes, respectively. For this purpose, creep rate equations available from literature were extrapolated up to $1000^{\circ} \mathrm{C}$ ([10], [40] and [46]), down to $2 \mathrm{MPa}$ ([10], [12] and [46]) and up to $3.2 \mathrm{wt} . \%$ of oxygen ([10], [12], [40] and [46]). Under a stress level of $20 \mathrm{MPa}$, oxygen-induced strengthening predicted by Eq. (1) $(B=2.29)$ is lower than those reported in [12] for Zircaloy-4 ( $B=2.8)$ and in [10] for Zircaloy-2 ( $B=3.42$ ), yet for oxygen contents and temperatures lower than those of the present study. This might be due to a saturation of oxygen-induced strengthening for contents higher than $1.5 \mathrm{wt} . \%$ or to a reduction in strengthening with increasing temperature. For a stress level of $2 \mathrm{MPa}$, predictions from Eq. (1) significantly differ from those of literature models, due to the linear creep regime, observed here for the first time in a highly enriched material. As a consequence, models proposed in [10], [12] and [46] should not be extrapolated without caution to low stress levels. 

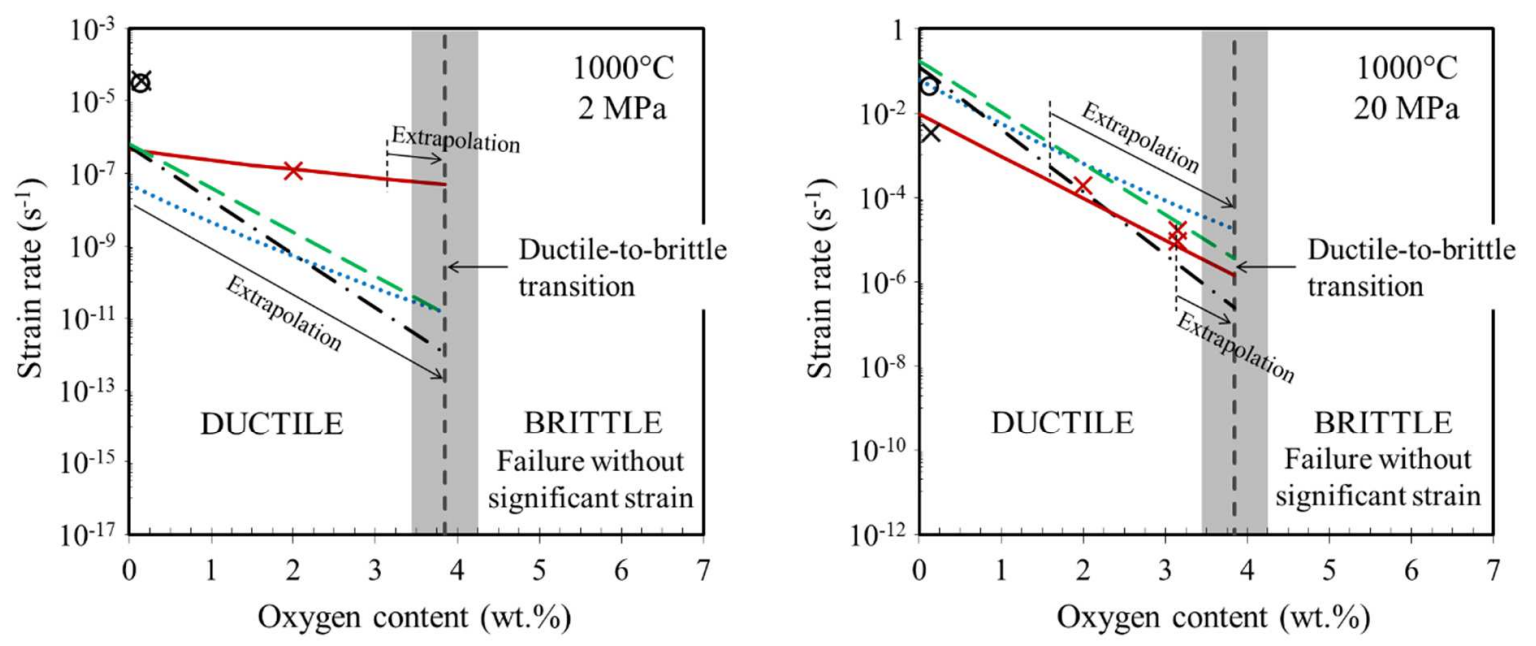

$$
\begin{aligned}
& \text { Tests }\left\{\times \text { Model } \alpha_{\mathrm{Zr}}(\mathrm{O})\right. \text { material (this study) }
\end{aligned}
$$

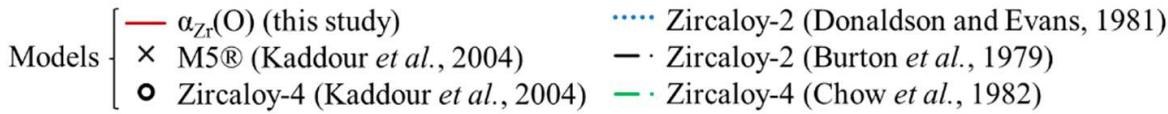

FIG. 6-Effect of oxygen on the viscoplastic strain rate of $\alpha_{\mathrm{Zr}}(\mathrm{O})$ at $1000^{\circ} \mathrm{C}$ under 2 and $20 \mathrm{MPa}$ estimated using the model developed in the present study and those proposed by Burton et al. [10] and Donaldson and Evans [46] for Zircaloy-2, Kaddour et al. [40] and Chow et al. [12] for Zircaloy-4 and Kaddour et al. [40] for M5®.

Influence of microstructural features - The presence of up to $15 \%$ of untransformed $\beta_{\mathrm{Zr}}$ phase, reported in the previous section is expected to induce two competing effects: on the one hand, the $\beta$ Zr phase is softer than the $\alpha \mathrm{Zr}(\mathrm{O})$ phase; on the other hand, partition of oxygen leads to oxygen enrichment in the $\alpha_{\mathrm{Zr}}(\mathrm{O})$ phase i.e. to further strengthening. These effects were tentatively quantified for the model material containing $2 \mathrm{wt} . \%$ of oxygen, tested above $1000^{\circ} \mathrm{C}$, by using an (inverse) homogenization approach with a Taylor assumption. The macroscopic axial strain rate, $\dot{\mathrm{E}}$, and the axial strain rates of $\alpha_{\mathrm{Zr}}(\mathrm{O})$ and $\beta_{\mathrm{Zr}}$ phases, respectively denoted as $\dot{\varepsilon}_{\alpha_{Z r}(O)}$ and $\dot{\varepsilon}_{\beta_{z r}}$, were assumed to be equal:

$$
\dot{\mathrm{E}}=\dot{\varepsilon}_{\alpha_{Z r}(O)}=\dot{\varepsilon}_{\beta_{Z r}}
$$

The macroscopic axial stress, $\Sigma$, was assumed to depend on axial stresses, $\sigma_{\alpha_{z r}(O)}$ and $\sigma_{\beta_{z r}}$ within $\alpha_{Z r}(O)$ and $\beta_{Z r}$ phases, respectively, and on the volume fraction of the $\beta_{\mathrm{Zr}}$ phase, $f_{\beta_{z r}}$ :

$$
\Sigma=\left(1-f_{\beta_{z r}}\right) \cdot \sigma_{\alpha_{Z r}(O)}+f_{\beta_{z r}} \sigma_{\beta_{Z r}}
$$

The mechanical behavior of the $\beta$ Zr phase was described by the power-law model proposed in [40] for $\mathrm{Zr}-1 \mathrm{wt} . \% \mathrm{Nb}-0.14 \mathrm{wt} . \% \mathrm{O}$, modified to take niobium enrichment into account. Trego [45] reported that an increase in niobium content from 1 to $2.25 \mathrm{wt} . \%$ reduced the creep rate of the $\beta_{\mathrm{Zr}}$ phase by $\sim 50 \%$. The enrichment of $\beta_{\mathrm{Zr}}$ in niobium is larger in the present case. However, in the absence of additional data, a factor 0.5 was applied to the strain rate predicted by the model described in [40], so that the $\beta_{Z \text { Zr }}$ phase creep rate and softening effect were probably slightly overestimated. Parameters of the power-law equation that describes the flow behavior of the 
$\alpha \mathrm{Zr}(\mathrm{O})$ phase itself were then adjusted by using an iterative process so that the macroscopic response of the model for the homogenized material fitted the experimental results obtained for the model $\left(\alpha_{\mathrm{Zr}}(\mathrm{O})+\beta_{\mathrm{Zr}}\right)$ samples. As reported in Table 3 , the behavior of the model $\alpha_{\mathrm{Zr}}(\mathrm{O})$ material is close to that of the $\alpha_{\mathrm{Zr}}(\mathrm{O})$ phase alone, of same oxygen content: the strain rate is reduced by a factor less than 2 due to the softness of the $\beta_{Z r}$ phase. The strengthening effect of oxygen partition between $\alpha_{\mathrm{Zr}}(\mathrm{O})$ and $\beta_{\mathrm{Zr}}$ was evaluated using Eq. (1) with parameters in Table 2 and chemical composition from abovementioned thermodynamic calculations for a mean oxygen content of $2 \mathrm{wt} . \%$. As shown in Table 3, the resulting increase in oxygen content by $0.25 \mathrm{wt} . \%$ leads to a reduction of the creep rate of the $\alpha_{\mathrm{Zr}}(\mathrm{O})$ phase itself by a factor 2 . As a result, both softening and strengthening effects of the two-phase microstructure of this material on the strain rate are small (negligible below $1000^{\circ} \mathrm{C}$ and a factor 2 at $1100^{\circ} \mathrm{C}$ ) and compensate each other in the high stress creep regime. As a consequence, the viscoplastic flow behavior of the model materials is considered as representative of that of single-phase $\alpha_{\mathrm{Zr}}(\mathrm{O})$ having the same chemical composition. The two-phase microstructure is thus not explicitly taken into account in the following. Only the values of the creep model parameters directly tuned on the data obtained on the model oxygen-enriched materials (Table 2) were used.

TABLE 3-Estimated effects of residual $\beta_{Z r}$ phase on the enrichment in oxygen of the $\alpha_{Z r}(O)$ phase, and on the strain rate (multiplicative factors) of the model $\alpha_{\mathrm{Zr}}(O)$ material with a mean oxygen content of 2 wt. $\%$.

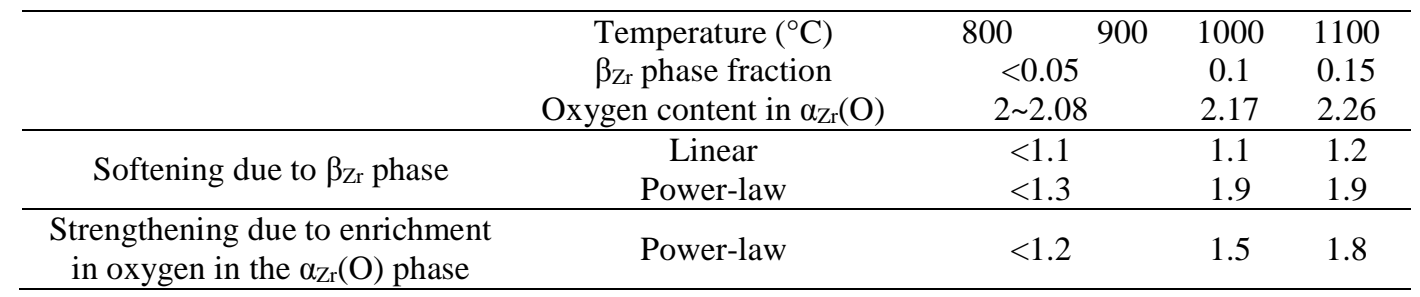

\section{Fracture of the model $\alpha_{Z r}(O)$ materials}

Macroscopic ductility-The maximal axial strain values recorded during the axial tensile creep tests are reported in Fig. 7. These values are lower bounds of the actual fracture strain. In most cases, due to the reduction in diameter associated with axial elongation, the alumina rings used for monitoring elongation fell once the axial strain reached 4 to $10 \%$, i.e., well before fracture. From Fig. 7, model $\alpha_{\mathrm{Zr}}(\mathrm{O})$ materials with oxygen contents between 2 and $3.4 \mathrm{wt} . \%$ are ductile between 800 and $1100^{\circ} \mathrm{C}$. Specimens containing more than 4 wt. $\%$ of oxygen failed in a brittle manner, even at $1100^{\circ} \mathrm{C}$. A ductile-to-brittle transition thus occurs at $1000 \sim 1100^{\circ} \mathrm{C}$ for oxygen contents between 3.4 and $4.3 \mathrm{wt}$. $\%$. 


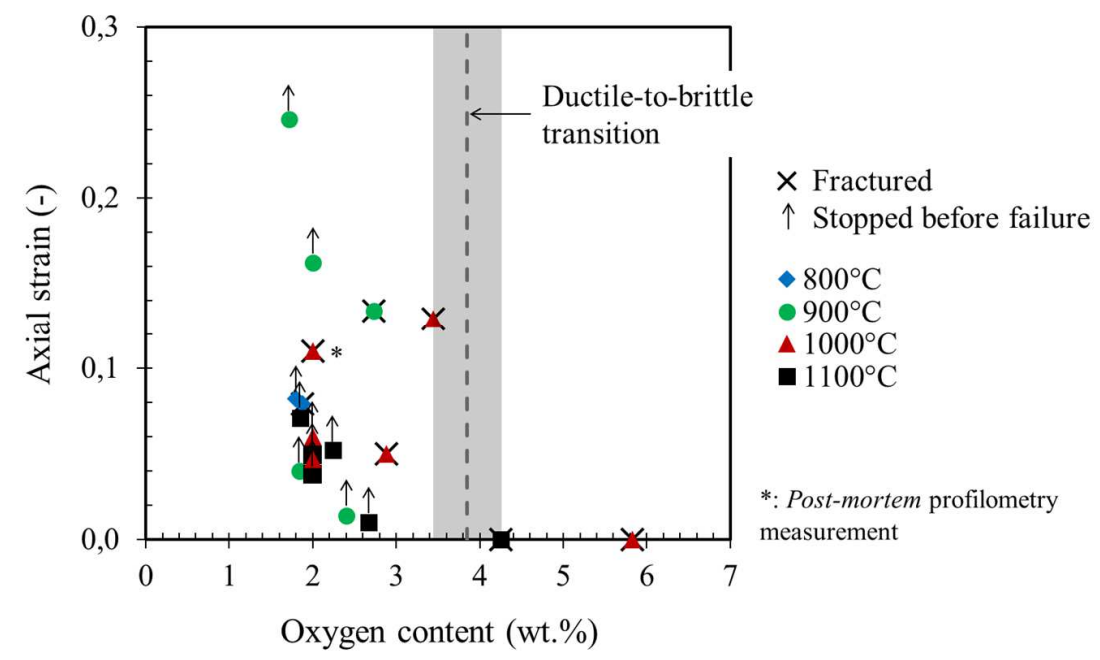

FIG. 7-Evolution of the maximal measured axial strain (lower bound of fracture strain) as a function of the oxygen content and test temperature of the $\alpha_{\mathrm{Zr}}(O)$ model materials tested under tensile creep.

Physical fracture mechanisms-Scanning Electron Microscopy (SEM) observation of the fracture surfaces of creep specimens with 2 and $3.4 \mathrm{wt}$.\% of oxygen shows that the fracture mode was not the same at the outer periphery, where oxide and $\alpha_{\mathrm{Zr}}(\mathrm{O})$ phases were located after oxidation, and for the rest of the specimens where the $\alpha \mathrm{Zr}(\mathrm{O})$ phase was formed during homogenization (Fig. 8). This highlights an effect of the oxidation, then homogenization processing route used to prepare these model materials. Nevertheless, the microstructure (chemical partitioning, texture and grain morphology) could not be differentiated between these regions. This difference in fracture behavior might be due to the existence of finer and disoriented subgrains linked to the structure of the parent oxide phase layer, to possible shortrange ordering for particular oxygen concentration ranges and/or to defects (cavities, microcracks, ...) resulting from phase transformation of zirconia into $\alpha \mathrm{Zr}(\mathrm{O})$ during homogenization, associated with a significant volume decrease (by $\sim 50 \%$ ).

At the outer periphery, brittle fracture occurred nearly perpendicular to the loading direction. A network of steps, oriented along a reduced number of directions, was evidenced on these outer cracks. These steps could be due to either cleavage fracture along different planes or to stress relaxation by localized slip, probably after fracture. With the exception of the sample outer periphery, considerable reduction in thickness, up to almost $100 \%$, was measured for samples with 2 and 3.4 wt. $\%$ of oxygen. Large $(>20 \mu \mathrm{m})$ elliptical dimples were also locally observed. A longitudinal cross-section of a sample containing $2 \mathrm{wt} . \%$ of oxygen, fractured at $900^{\circ} \mathrm{C}$ revealed that the $\alpha \mathrm{zr}(\mathrm{O})$ phase can withstand high strain levels in these conditions. Due to its much lower oxygen content, the (prior-) $\beta_{Z \text { r }}$ phase, which formed a nearly continuous network in the model material containing $2 \mathrm{wt} . \%$ oxygen, probably facilitates strain accommodation between $\alpha_{\mathrm{Zr}}(\mathrm{O})$ platelets, leading to higher macroscopic ductility. Steps similar to those observed in the nearly brittle outer zones were present on the dimple walls and also in the bottom part of the dimples (Fig. 8(a)). This suggests that these steps might be due to (localized) slip rather than to cleavage. Angles of 90 and $120^{\circ}$ between these steps are consistent with angles between known slip planes of the $\alpha_{\mathrm{Zr}}$ hexagonal structure. 

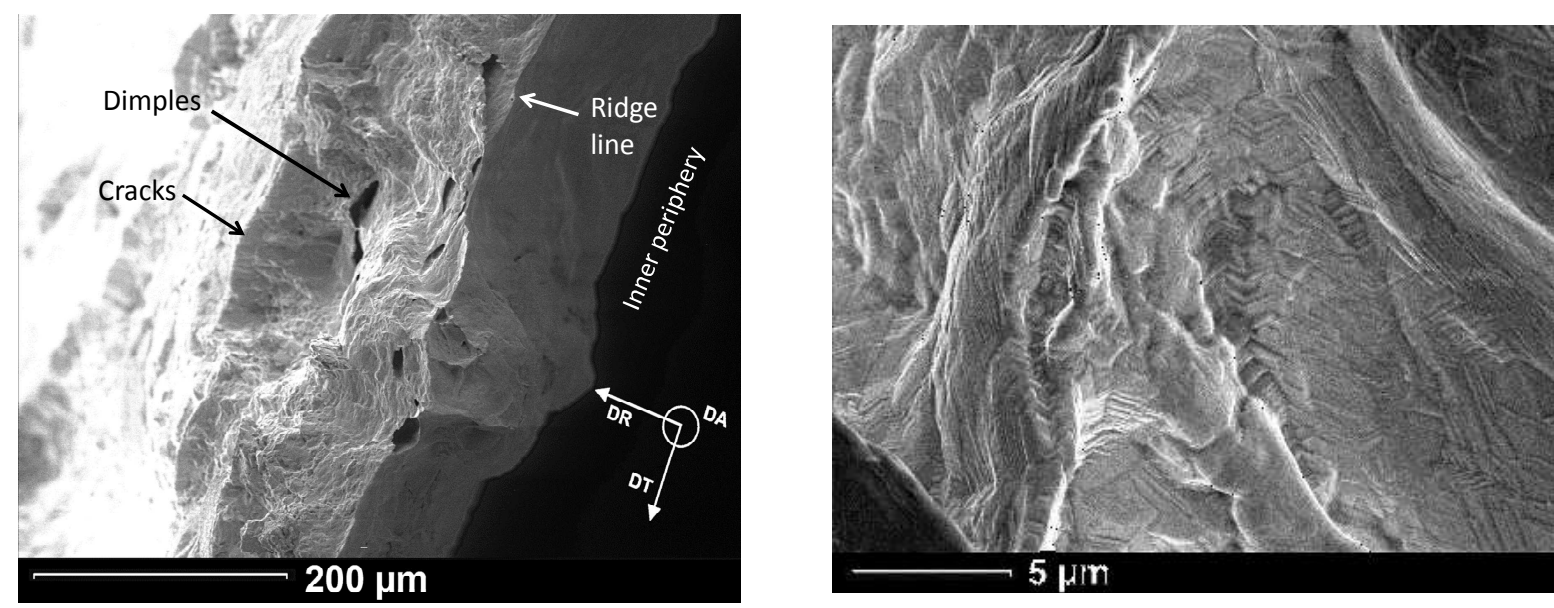

(a)
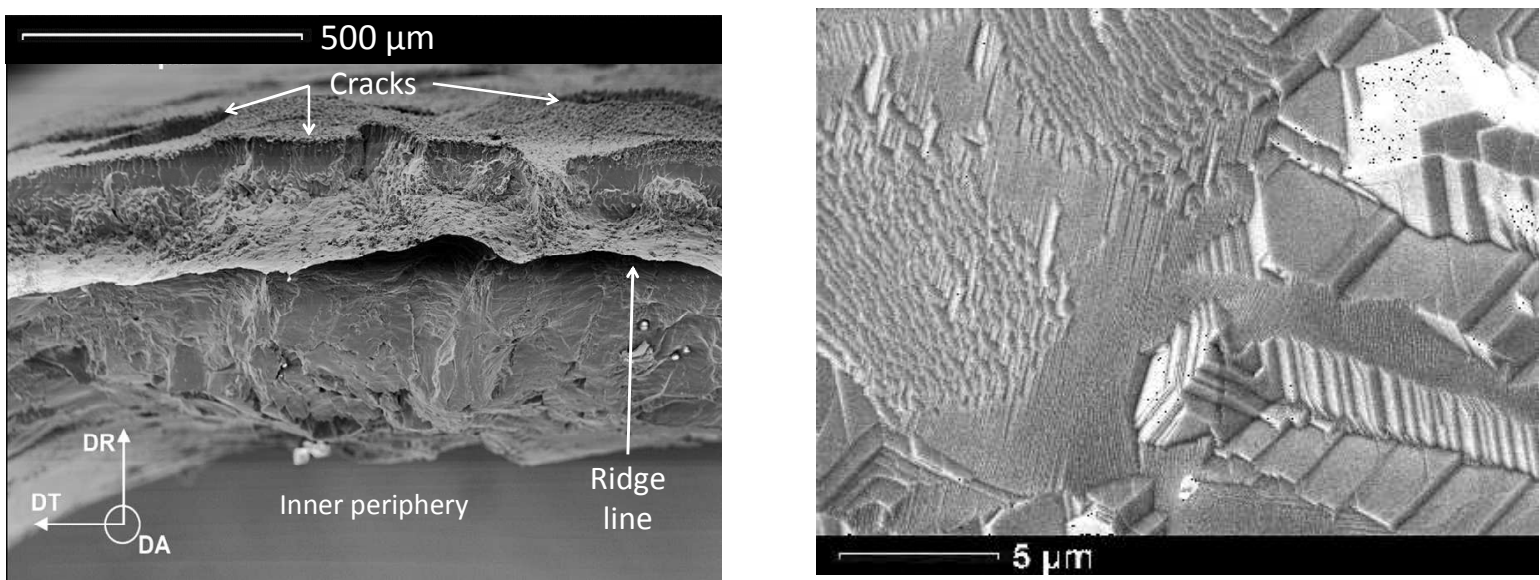

(b)

FIG. 8-SEM fractographs of $\alpha_{Z r}(O)$ specimens containing (a) 2 wt. \% of oxygen (right figure: enlarged view inside a dimple) and (b) $3.4 \mathrm{wt} . \%$ of oxygen (right figure: enlarged view of a nearly brittle zone) fractured at $1000^{\circ} \mathrm{C}$.

Model materials with more than 4 wt.\% of oxygen exhibited a purely brittle behavior above $1000^{\circ} \mathrm{C}$. In the specimen containing $4.3 \mathrm{wt} . \%$ of oxygen, grains were very coarse and fracture was mainly intergranular (Fig. 9(a)). A 50- $\mu$ m-thick layer of $\alpha_{\mathrm{Zr}}(\mathrm{O})$ phase (chemistry confirmed by EPMA) with an atypical columnar morphology was observed at the outer periphery. This further suggests that the initial microstructure of the oxidized material was not completely "erased" during the homogenization step. In the material with $5.8 \mathrm{wt} . \%$ of oxygen, a thin residual columnar zirconia layer, broken by intergranular fracture, was observed at the outer periphery. The $\alpha \mathrm{Zr}(\mathrm{O})$ phase mainly fractured by cleavage and exhibited river patterns (Fig. 9(b)). Some regions exhibited a flat and smooth appearance, suggesting intergranular fracture. Such mixed (cleavage + intergranular) brittle fracture observed at HT (oxygen content higher than $4.3 \mathrm{wt} . \%$ ) looks like the fracture surface reported by Garde et al. [50] for Zircaloy-4 containing $2.3 \mathrm{wt} . \%$ of oxygen and tested at $850^{\circ} \mathrm{C}$; the comparison cannot go further due to fracture conditions missing in [50]. 

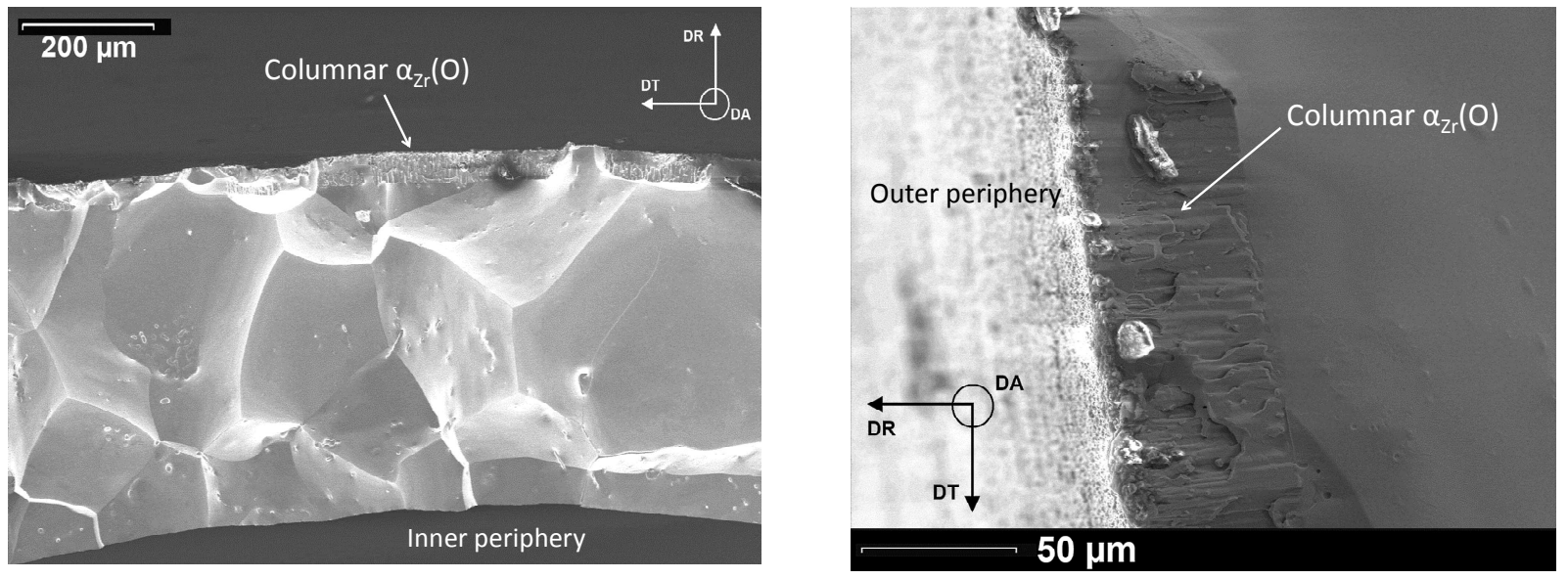

(a)
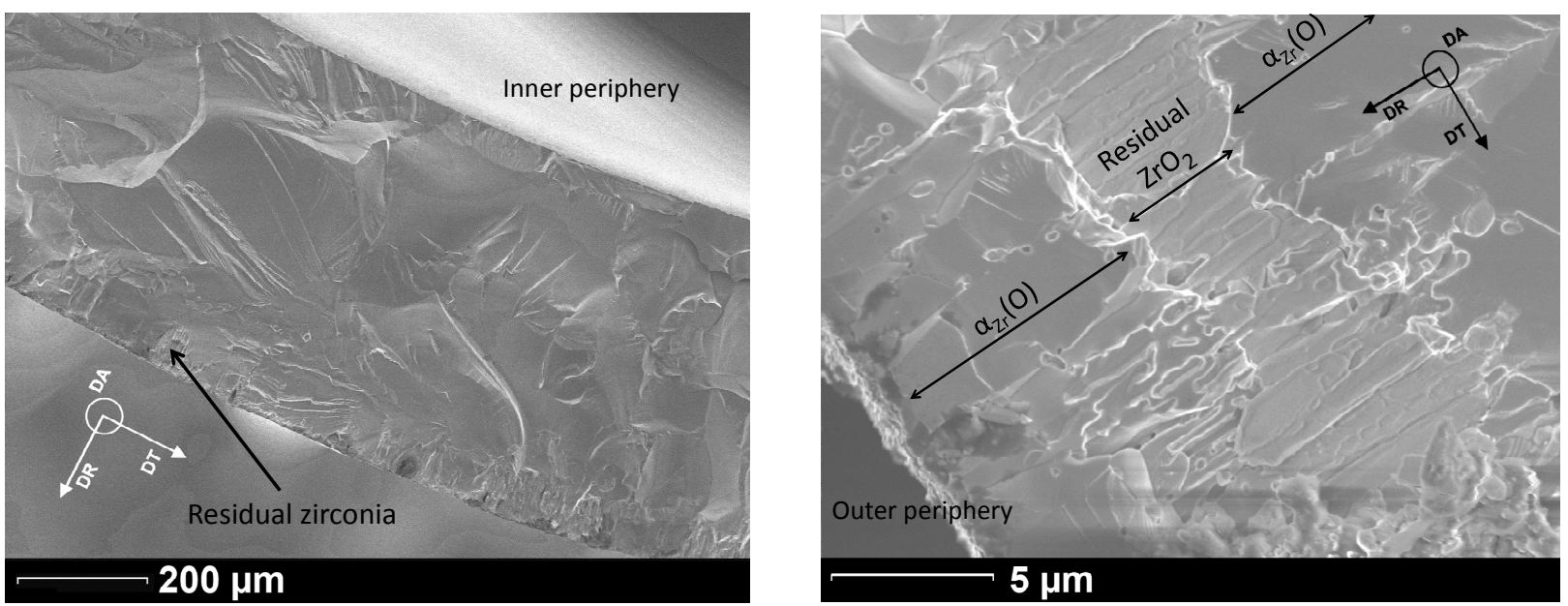

(b)

FIG. 9-SEM fractographs of (a) an $\alpha_{Z r}(O)$ sample containing $3.4 \mathrm{wt} . \%$ of oxygen, fractured at $1100^{\circ} \mathrm{C}(\mathrm{right}$ image: detailed view of $\alpha_{\mathrm{Zr}}(O)$ on the tube external periphery) and (b) an $\alpha_{\mathrm{Zr}}(\mathrm{O})$ sample containing $5.8 \mathrm{wt} . \%$ of oxygen fractured at $1000^{\circ} \mathrm{C}$ (right image: enlarged view of residual zirconia within the $\alpha_{\mathrm{Zr}}(\mathrm{O})$ layer).

\section{Modeling the high temperature creep behavior of an oxidized cladding}

Model description-In order to assess the strengthening effect of oxidation on the HT creep behavior of fuel cladding, a model was implemented into the finite element code Cast3M developed at $\mathrm{CEA}^{8}$. The purpose was to calculate the mechanical response of an oxidized cladding subjected to internal pressure at $\mathrm{HT}\left(1000\right.$ and $\left.1100^{\circ} \mathrm{C}\right)$ and to compare the predictions to available results of tests performed in a steam environment in the EDGAR facility [38] on Zircaloy-4 and M5® cladding specimens.

The oxidized cladding was represented as a three-layer material: an outer oxide layer, an $\alpha_{\mathrm{Zr}}(\mathrm{O})$ layer and an inner $\beta_{\mathrm{Zr}}$ substrate. In this first approach, mechanical properties of all layers

\footnotetext{
${ }^{8} \mathrm{http}: / / \mathrm{www}-\mathrm{cast} 3 \mathrm{~m} . \mathrm{cea} . \mathrm{fr} /$
} 
were assumed to be isotropic. The growth of the oxide and $\alpha_{\mathrm{Zr}}(\mathrm{O})$ phase layers, as well as damage and fracture were not simulated. Instead, parametric calculations were carried out by varying the thickness of the layers in the (undeformed) mesh; the thickness of the oxide and $\alpha_{\mathrm{Zr}}(\mathrm{O})$ phase layers were set as a function of time from available kinetics data [3][33][39]. The layers were supposed to be perfectly adherent to each other and separated by smooth interfaces. Oxidation-induced internal stresses, thermal strains and strains due to phase transformations as well as oxide growth or oxygen ingress into the metal were not considered. From experimental results presented in the present paper, the $\alpha_{\mathrm{Zr}}(\mathrm{O})$ phase is brittle at HT when its oxygen content exceeds $\sim 4 \mathrm{wt} . \%$. Thus it could be reasonably expected that in an oxidized cladding, the part of the $\alpha \mathrm{zr}(\mathrm{O})$ phase layer that contains the highest oxygen content cracks at the very beginning of creep loading even if direct observations were not available. A parametric approach was thus adopted by considering three representations of the oxidized cladding:

- a two-layer $\left(\beta_{\mathrm{Zr}}+\alpha_{\mathrm{Zr}}(\mathrm{O})_{2-4}\right)$ model: only the $\beta_{\mathrm{Zr}}$ substrate and that part of the $\alpha_{\mathrm{Zr}}(\mathrm{O})$ layer containing less than $4 \mathrm{wt} . \%$ of oxygen (expected to be ductile) were considered to sustain the load;

- a two-layer $\left(\beta_{\mathrm{Zr}}+\alpha_{\mathrm{Zr}}(\mathrm{O})_{2-7}\right)$ model: the $\beta_{\mathrm{Zr}}$ substrate and the whole $\alpha_{\mathrm{Zr}}(\mathrm{O})$ layer were considered to sustain the load;

- a three-layer $\left(\beta_{\mathrm{Zr}}+\alpha_{\mathrm{Zr}}(\mathrm{O})_{2-7}+\mathrm{ZrO}_{2}\right)$ model: both the $\beta_{\mathrm{Zr}}$ substrate, $\alpha_{\mathrm{Zr}}(\mathrm{O})$ and oxide layers were taken into account.

For practical reasons, numerical simulations were performed in $3 \mathrm{D}$ and a small portion $\left(0.02^{\circ}\right.$ sector with a height of $2 \mu \mathrm{m}$ ) of the cladding was meshed (Fig. 10) by using quadratic brick elements with full integration. In the $\alpha_{\mathrm{Zr}}(\mathrm{O})$ and oxide layers, the mesh size along the radial direction was set to $1 \mu \mathrm{m}$ for layer thickness $<10 \mu \mathrm{m}$ and to $2 \mu \mathrm{m}$ otherwise. In the $\beta_{\mathrm{Zr}}$ substrate, the mesh size increased from that used for the $\alpha \mathrm{zr}(\mathrm{O})$ layer up to $20 \mu \mathrm{m}$ near the inner surface. The spatial distribution of oxygen across the wall thickness was represented by introducing a local oxygen concentration at Gauss points (Fig. 10). A linear oxygen concentration gradient was assumed across the $\alpha \mathrm{Zr}(\mathrm{O})$ phase layer (from $2 \mathrm{wt} . \%$ at the interface with the $\beta_{\mathrm{Zr}}$ layer to 4 or $7 \mathrm{wt} . \%$ at the opposite surface, according to the selected configuration).

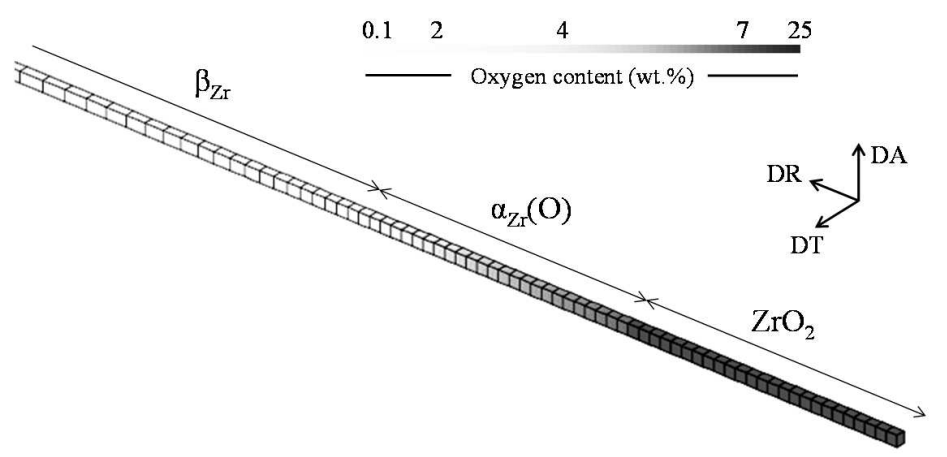

FIG. 10-Example of mesh and oxygen concentration field used for finite element simulations for the three-layer $\left(\beta_{\mathrm{Zr}}+\alpha_{\mathrm{Zr}}(\mathrm{O})_{2-7}+\mathrm{ZrO}_{2}\right)$ model.

Standard symmetry conditions were applied to the nodes of the upper, lower and lateral surfaces. From a preliminary experimental study of specimens subjected to internal pressure creep, the prescribed zero-axial-displacement condition along the tube axis was representative of the mechanical response of an isotropic cladding material subjected to a closed-end internal 
pressurization test. An internal pressure, updated at each time-step in order to account for the updated geometry, was applied to the inner surface. The calculations were performed by using an updated Lagrangian method. A variable time-step between 0.1 and 200 s was used for the investigated range of creep rates $\left(10^{-2}-10^{-8} \mathrm{~s}^{-1}\right)$. It was checked that the mesh sizes and the timesteps used were small enough to guarantee that the results were not significantly affected by the spatial and temporal discretization.

In the constitutive equations, the total strain was additively decomposed into elastic and viscoplastic strains. Elastic strains were calculated via an isotropic Hooke's law with Young's moduli of respectively $44 \mathrm{GPa}$ for $\beta_{\mathrm{Zr}}$ and $\alpha_{\mathrm{Zr}}(\mathrm{O})$ layers, and $200 \mathrm{GPa}$ for $\mathrm{ZrO}_{2}$, and a Poisson's ratio of 0.3 for all layers. Due to missing information about viscoplastic flow anisotropy of any layer, a von Mises equivalent was used to calculate the viscoplastic potential. An additive combination of the viscoplastic strain rate tensors from the two viscoplastic deformation regimes (i.e., linear and power-law) was used. Both of these tensors were obtained by assuming the normality rule, and thus were associated with the same flow direction. The plastic multipliers were given for each regime by the flow equations in the form of Eq. (1). The viscoplastic behavior of the $\beta_{\text {Zr }}$ phase was described by the flow equation proposed in [40] for Zircaloy- 4 and by those presented in [40] and [45] for M5®. The flow equation (Eq. (1)) with parameters in Table 2 was used to describe the oxygen-dependent viscoplastic behavior of the $\alpha_{\mathrm{Zr}}(\mathrm{O})$ phase. The HT viscoplastic behavior of the oxide layer was estimated using a power-law equation with parameters tuned on the basis of results of HT creep compression tests on a bulk, industrial doped monoclinic and tetragonal zirconia [51][52][53]; the following adjusted values were found for parameters in Eq. (1): $A=5.08 \cdot 10^{15} \mathrm{~K}_{\mathrm{Mpa}} \mathrm{Mp}^{-\mathrm{s}} \cdot \mathrm{s}^{-1}, n=1.52, Q=500 \mathrm{~kJ} \cdot \mathrm{mol}^{-1}, B=0$.

According to these data, the creep rate of $\mathrm{ZrO}_{2}$ is within the range of values expected for the $\alpha_{\mathrm{Zr}}(\mathrm{O})$ phase. Yet, this flow equation certainly provides a very rough representation of the behavior of the oxide layer of interest here, whose chemical composition and microstructure are very different from those of industrial doped zirconia.

Results and discussion-As shown in Fig. , the $\left(\beta_{\mathrm{Zr}}+\alpha_{\mathrm{Zr}}(\mathrm{O})_{2-4}\right)$ model, only considering that part of the $\alpha_{\mathrm{Zr}}(\mathrm{O})$ phase layer expected to be ductile, strongly underestimates the gradual reduction in strain rate observed during internal pressure creep tests under HT steam. Experimental strain rates are slightly underestimated by the $\left(\beta \mathrm{Zr}+\alpha \mathrm{Zr}(\mathrm{O})_{2-7}\right)$ model that considers the whole $\alpha_{\mathrm{Zr}}(\mathrm{O})$ phase layer to sustain the load. Additional strengthening brought by the oxide layer $\left(\left(\beta_{\mathrm{Zr}}+\alpha_{\mathrm{Zr}}(\mathrm{O})_{2-7}+\mathrm{ZrO}_{2}\right)\right.$ model $)$ appeared to be limited (factor 2 on the creep rate) but enables fairly well reproducing the experimental creep strain of the cladding. Similar results were obtained by comparing similar numerical simulations to (unpublished) experimental creep of Zircaloy-4 and M5 $\otimes$ claddings at 1000 and $1100^{\circ} \mathrm{C}$. This suggests a posteriori that the $\alpha_{\mathrm{Zr}}(\mathrm{O})$ phases formed in Zircaloy-4 and M5® could have comparable microstructures and viscoplastic behavior under these conditions. 


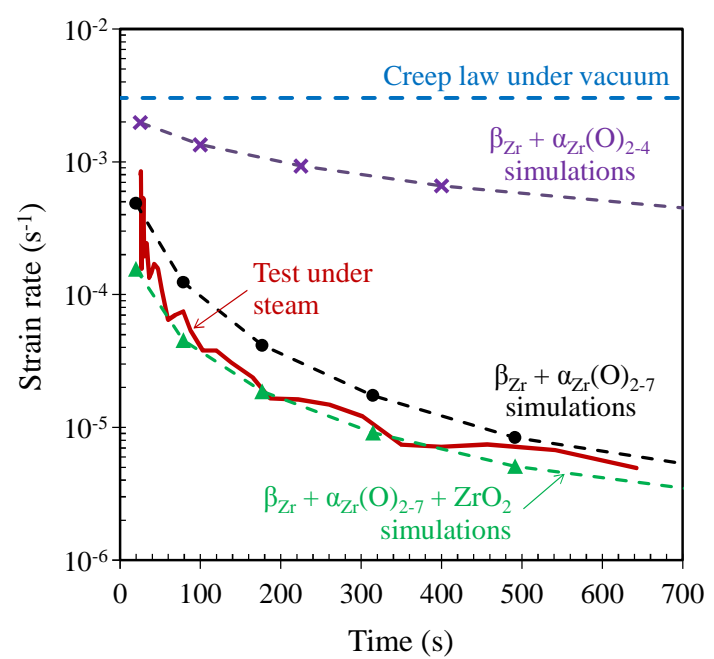

FIG. 11-Evolution of the viscoplastic strain rate of a Zircaloy-4 cladding specimen creep tested in steam at $1100^{\circ} \mathrm{C}$ under a 5 bar internal pressure: experimental result, prediction from the creep model presented in [40] for a non-oxidized cladding (tested in a vacuum) and predictions from the three finite element models.

As the deformation mechanism associated with the linear creep regime of the $\alpha \mathrm{Zr}(\mathrm{O})$ phase, and thus its grain size sensitivity, could not be identified, Eq. (1) did not take grain size sensitivity into account. In order to evaluate the impact of this assumption on the results reported in Fig. 11, the creep flow equation of the $\alpha_{\mathrm{Zr}}(\mathrm{O})$ phase in the linear regime was modified by adding a cubic dependence on the grain size (Coble-type diffusional flow). A reference grain size of $66 \mu \mathrm{m}$ was chosen to fit data on model materials. Based on microstructural observations of oxidized claddings, a range of grain sizes equal to that of the thickness of the $\alpha_{\mathrm{Zr}}(\mathrm{O})$ layer (2$70 \mu \mathrm{m})$ was considered. The results obtained with the two-layer $\left(\beta_{\mathrm{Zr}}+\alpha_{\mathrm{Zr}}(\mathrm{O})_{2-7}\right)$ model are only slightly modified by the introduction of this grain size dependence.

As things stand at the moment, it is possible to correctly predict the mechanical behavior of the oxidized cladding with the proposed model but only by considering the contribution of the whole $\alpha_{\mathrm{Zr}}(\mathrm{O})$ layer $\left(\left(\beta_{\mathrm{Zr}}+\alpha_{\mathrm{Zr}}(\mathrm{O})_{2-7}\right)\right.$ or $\left(\beta_{\mathrm{Zr}}+\alpha_{\mathrm{Zr}}(\mathrm{O})_{2-7}+\mathrm{ZrO}_{2}\right)$ models $)$. This is in contradiction with fractography results from the present study. Moreover, numerical simulations predict high stress levels (up to $\sim 200 \mathrm{Mpa}$ ) in the outer part of the $\alpha_{\mathrm{Zr}}(\mathrm{O})$ layer. Such high stresses should induce fracture and that part is not expected to sustain the load all along the test. To solve this issue, there is still a need in experimental data about internal stresses generated by oxidation, anisotropy in viscoplastic behavior of the $\alpha_{\mathrm{Zr}}(\mathrm{O})$ phase, viscoplastic behavior of the zirconia layer and/or interaction between oxidation and viscoplastic deformation.

\section{Conclusion about the effect of oxygen on the viscoplastic flow and fracture behavior of $\alpha z r(O)$}

The mechanical behavior of the $\alpha_{\mathrm{Zr}}(\mathrm{O})$ phase at HT was investigated through axial tensile creep tests performed under vacuum between 800 and $1100^{\circ} \mathrm{C}$ on model materials, fabricated from M5® cladding, homogeneously enriched in oxygen at various contents between 2 and $5.8 \mathrm{wt} . \%$. The $\alpha_{\mathrm{Zr}}$ phase is significantly strengthened and embrittled by oxygen. For the first time, two creep regimes were observed depending on applied stress level. Creep and failure mechanisms have been discussed. A ductile-to-brittle transition was observed at $1000-1100^{\circ} \mathrm{C}$ for oxygen 
contents between 3.4 and $4.3 \mathrm{wt} . \%$. The contribution of the $\alpha_{\mathrm{Zr}}(\mathrm{O})$ phase layer to the creep behavior of an oxidized fuel cladding tube subjected to internal pressure at HT was evaluated by finite element analysis.

\section{Mechanical behavior of the highly hydrogen-enriched (prior-) $\beta \mathrm{Zr}$ phase}

\section{Materials and experimental procedures}

Sample preparation - In order to study the effect of high hydrogen contents ( $\leq 3200$ wt.ppm) on the mechanical properties of the (prior-) $\beta_{Z \text { zr }}$ phase, model hydrogen-enriched samples were produced from as-received stress-relieved, low tin Zircaloy-4 cladding tubes (outer diameter and thickness of $\sim 9.5 \mathrm{~mm}$ and $0.57 \mathrm{~mm}$, respectively) supplied by AREVA NP. The material initially contained $\sim 0.13 \mathrm{wt} . \%$ of oxygen and less than $5 \mathrm{wt} . \mathrm{ppm}$ of hydrogen (Table 1). 60 -mm-long cladding tube samples were charged in hydrogen at $800^{\circ} \mathrm{C}$ in a furnace in a flowing mixture of argon and hydrogen, then cooled down to room temperature at a few ${ }^{\circ} \mathrm{C} / \mathrm{min}$.

The hydrogen content was measured for each sample by using an inert gas fusion thermal conductivity technique (various analyzers were used: HORIBA ${ }^{\circledR 9}{ }^{9}$ EMGA-821, HORIBA ${ }^{\circledR}$ EMGA-921, and LECO ${ }^{10}{ }^{10}$ RH404). Hydrogen contents were also determined on a selected number of samples by differential scanning calorimetry, micro elastic recoil detection analysis ( $\mu$-ERDA) (CEA Saclay/DSM/IRAMIS/SIS2M/LEEL) [28][29] and neutron radiography (CEA Saclay/DEN/DRSN/SEROS). The measured hydrogen contents ranged from 1700 to $3200 \mathrm{wt}$. $\mathrm{ppm}$. The relative uncertainty on hydrogen content was estimated to $\pm 15 \%$ for the highest hydrogen contents investigated here. It was checked that homogeneity of hydrogen content within the samples was satisfactory for the present application. Infrared absorption analyses (LECO TC500 analyzer) showed slight oxygen uptake ( 0.07 $\pm 0.02 \mathrm{wt} . \%)$ after charging, so that hydrogen-charged samples contained $\sim 0.21 \pm 0.01 \mathrm{wt} . \%$ of oxygen in average.

Microstructure of the model materials right after hydrogen charging-To characterize the properties of the transformed $\beta_{\mathrm{Zr}}$ phase, a heat-treatment in the $\beta_{\mathrm{Zr}}$ phase domain was applied to the specimens before mechanical testing. However, it is interesting to briefly discuss the microstructure of the material right after hydrogen charging. Observations by optical microscopy and SEM and chemical micro-analysis by EPMA performed on selected samples did not evidence any oxide layer. However, thin layers of $\alpha_{\mathrm{Zr}}(\mathrm{O})$ phase were observed at the sample surfaces, in accordance with the above mentioned slight oxygen uptake.

\footnotetext{
${ }^{9}$ HORIBA is a registered trademark of HORIBA Ltd in the USA or other countries

${ }^{10}$ LECO is a registered trademark of LECO CORPORATION in the USA or other countries
} 


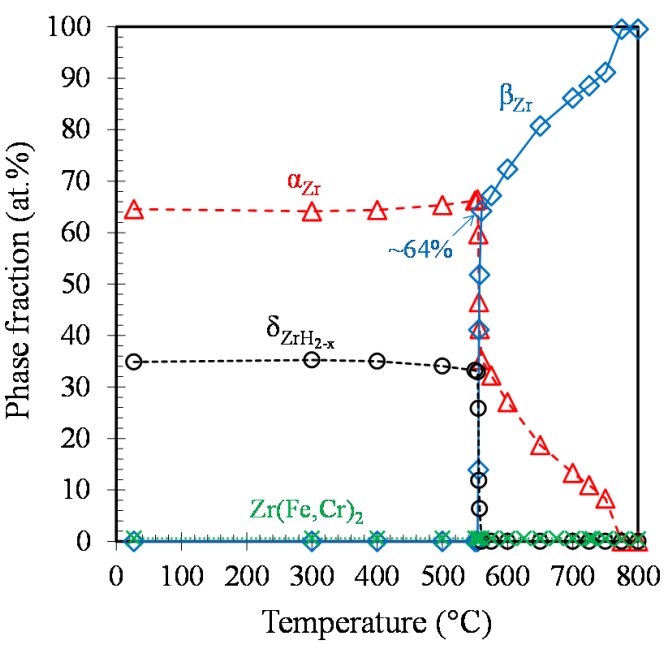

(a)

(b)

FIG. 12-(a) Optical micrograph of a transverse cross-section right after hydrogen-charging at $800^{\circ} \mathrm{C}$ (and cooling at a few ${ }^{\circ} \mathrm{C} / \mathrm{min}$ ) of a Zircaloy-4 sample containing $~ 3200$ wt.ppm of hydrogen (and $\sim 0.2 \mathrm{wt} . \%$ of oxygen) and (b) calculated (Thermo-Calc ${ }^{\mathrm{TM}}+$ Zircobase) evolution of equilibrium phases volume fractions for Zircaloy-4 containing 3000 wt.ppm of hydrogen (and $0.14 \mathrm{wt} \%$ of oxygen) as a function of temperature.

The material microstructure right after hydrogen-charging depended on the mean hydrogen content. At $800^{\circ} \mathrm{C}$, the as-received material is still in the $\alpha \mathrm{Zr}$ phase. During hydrogen-charging at $800^{\circ} \mathrm{C}$, once the hydrogen content was high enough, the primary $\alpha$ zr phase progressively

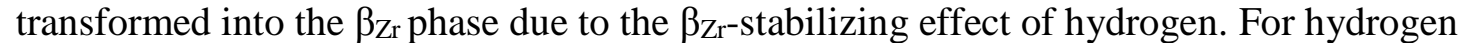
contents of 2000 and 3000 wt.ppm, the material was expected to have fully transformed into $\beta_{\mathrm{Zr}}$ phase at $800^{\circ} \mathrm{C}$. As illustrated in Fig. 12, at the beginning of cooling, above the eutectoid temperature $\left(\sim 550^{\circ} \mathrm{C}[42]\right)$, the $\beta_{\mathrm{Zr}}$ phase progressively transformed into proeutectoid $\alpha \mathrm{Zr}$ phase. The eutectoid reaction then lead to a fast transformation of the residual $\beta_{\mathrm{Zr}}$ grains into $\alpha \mathrm{Zr}$ grains. As a consequence, the material right after hydrogen-charging at $800^{\circ} \mathrm{C}$ up to $\sim 2000$ and 3000 wt.ppm was a mixture of proeutectoid $\alpha_{\mathrm{Zr}}$ phase and of $\alpha_{\mathrm{Zr}}$ phase that appeared below the eutectoid temperature (corresponding respectively to the lighter and darker regions in Fig. 12(a)). As a result of solute element partitioning, the former was enriched in $\alpha_{Z \mathrm{r}}$-stabilizers (including oxygen) and depleted in $\beta_{Z \mathrm{r}}$-stabilizers (including hydrogen), and the latter was depleted in $\alpha_{\mathrm{Zr}^{-}}$

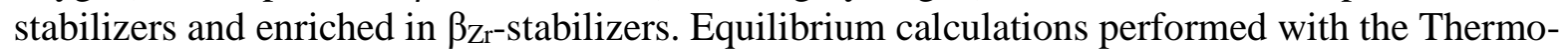
Calc ${ }^{\mathrm{TM}}$ software using the Zircobase database [42] (Fig. 12) showed that the $\beta_{\mathrm{Zr}}$ phase volume fractions just above the eutectoid transformation are $\sim 45$ and $65 \%$ for the materials containing respectively 2000 and $3000 \mathrm{wt}$.ppm of hydrogen in average. This is in accordance with the microstructures observed right after hydrogen-charging. For the sake of simplicity, hydrogencharged specimens are denoted as "hydrided" in the following.

Mechanical testing - Smooth tensile specimens with a gauge length of $8 \mathrm{~mm}$ and a gauge width of $2 \mathrm{~mm}$ (Fig. 13) were fabricated from both hydrided and non-hydrided cladding tubes. For each specimen, oxygen and hydrogen contents were measured respectively by infrared absorption (LECO $®$ TC500 analyzer) and thermal conductivity (LECO ${ }^{\circledR}$ TC500 and HORIBA ${ }^{\circledR}$ EMGA-921 analyzers) from the offcuts on both sides of the gauge region. 
The specimens were mounted on an electrical-mechanical uniaxial tensile machine equipped with a radiation furnace. The temperature was monitored by using three $\mathrm{Ni}-\mathrm{Cr} / \mathrm{Ni}-\mathrm{Al}$ thermocouples spot-welded on the grips. The temperature gradient along the specimen gauge region, and the temperature uncertainty and variation during the tests were expected to be lower than $10^{\circ} \mathrm{C}$, respectively. The specimens were quickly heated up to the $\beta_{\mathrm{Zr}}$ temperature domain (at $15^{\circ} \mathrm{C} / \mathrm{s}$ up to $800^{\circ} \mathrm{C}$ then at $\sim 3^{\circ} \mathrm{C} / \mathrm{s}$ up to $\sim 1200^{\circ} \mathrm{C}$ ) inside the facility, hold at HT for a few tens of seconds, then cooled down to the target tensile test temperature (between 700 and $20^{\circ} \mathrm{C}$ ), and immediately pulled in tension. The cooling rate was $\sim 5^{\circ} \mathrm{C} / \mathrm{s}$ between $1200^{\circ} \mathrm{C}$ and $700^{\circ} \mathrm{C}, 1{ }^{\circ} \mathrm{C} / \mathrm{s}$ around $500^{\circ} \mathrm{C}$ and $<1{ }^{\circ} \mathrm{C} / \mathrm{s}$ below. This thermal cycle involving cooling from the $\beta_{\mathrm{Zr}}$ temperature domain was used to guarantee that the microstructure and thus the mechanical behavior of the material were representative of those of the (prior-) $\beta_{\mathrm{Zr}}$ phase during cooling and quenching at the end of a LOCA-type transient.

The tests were performed in air so that a 5 10- $\mu \mathrm{m}$-thick oxide layer grew during heating at the specimen surfaces in order to prevent from hydrogen desorption. A 5 10- $\mu \mathrm{m}$-thick $\alpha_{\mathrm{Zr}}(\mathrm{O})$ layer also formed beneath the oxide layer and a limited amount of oxygen could have diffused into the $\beta_{\mathrm{Zr}}$ phase. The effect of this slight oxidation on results is discussed later in the paper. The tests were performed with prescribed displacement rate of $0.8 \mathrm{~mm} \cdot \mathrm{s}^{-1}$ i.e. initial average strain rate of $\sim 0.1 \mathrm{~s}^{-1}$. This relatively high strain rate was selected to minimize metallurgical evolutions and oxidation of the material during the tensile test itself. This loading rate is expected to be faster than the rates at which the cladding can be loaded during a LOCA transient.

In order to characterize the Young's modulus and plastic strain anisotropy, axial elongation and width reduction of the specimen gauge part were continuously measured before necking by using a 2D digital image correlation technique. A speckle was applied by using titanium dioxide based white fluid. The side surface of interest was observed under white light by an optical camera with an acquisition rate of 250 images per second. The VIC-2D ${ }^{\text {TM}} 11$ software was used for digital image correlation. Axial and hoop strains fields, respectively measured along specimen length and width directions were averaged over the gauge region. An accuracy better than $\pm 3 \cdot 10^{-4}$ is expected on mean strain measurements.

The $0.2 \%$ proof stress, ultimate tensile strength (UTS) and uniform elongation were determined from engineering stress-strain curves. The axial elongation measured by digital image correlation was used for the evaluation of Young's modulus. In order to characterize the ductility of the material, the reduction of area at fracture was optically measured with an absolute accuracy of about $\pm 8 \%$.

\footnotetext{
${ }^{11}$ VIC-2D is a trademark of Correlated Solutions, Inc.
} 

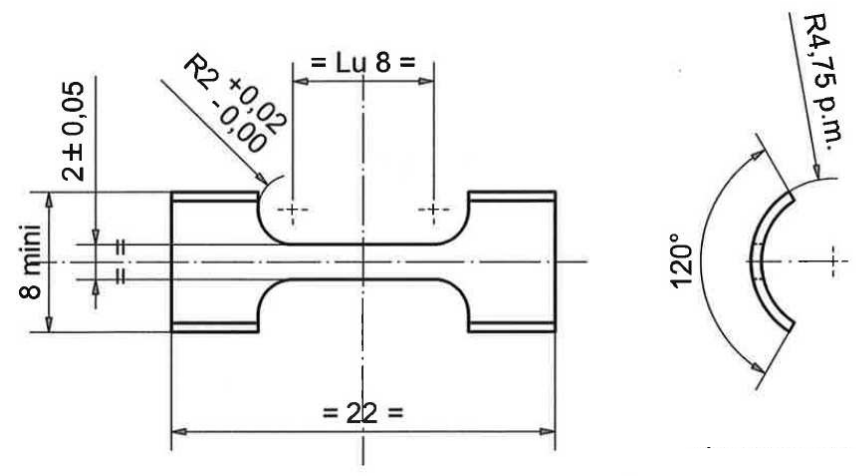

FIG. 13-Specimen geometry used for axial tensile tests on (prior-) $\beta_{Z r}$ materials (dimensions in mm).

\section{Results and discussion}

Elasticity-As illustrated in Fig. 14, the value of Young's modulus obtained at room temperature for the non-hydrided prior- $\beta_{\mathrm{Zr}}$ material is consistent with those measured in [14] by using a resonance method on prior- $\beta_{Z \mathrm{Zr}}$ samples fabricated from a Zircaloy- 4 sheet, and with those reported in [54] and [55] for the as-received material. From Fig. 14, the Young's modulus of the (prior-) $\beta_{\mathrm{Zr}}$ phase, whatever its hydrogen content, decreases with increasing temperature between 20 and $700^{\circ} \mathrm{C}$ in a way similar to that predicted by the correlations given in [54] and [55] for the as-received material.

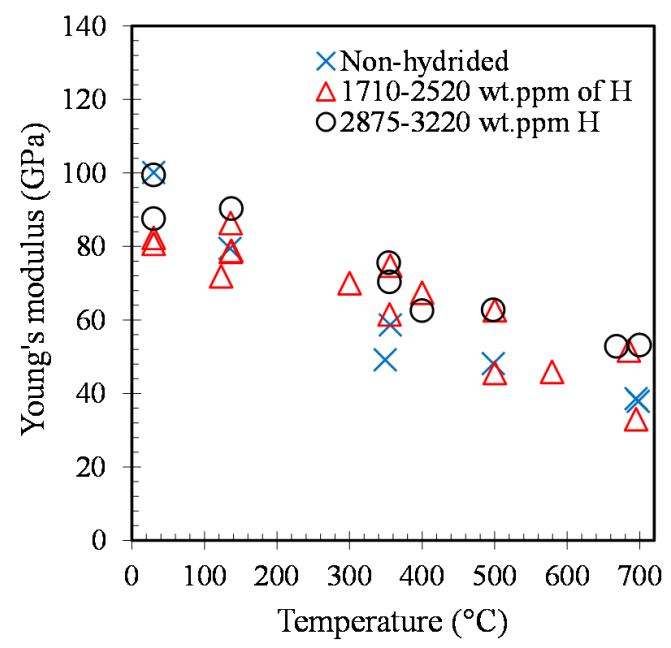

FIG. 14-Evolution as a function of temperature of the Young's modulus (accuracy of about \pm 10 Gpa) of model (prior-) $\beta_{Z r}$ materials, non-hydrided or containing between 1710 and 3220 wt.ppm of hydrogen (and at least 0.2 wt. \% of oxygen).

By taking the measurement uncertainty and scatter into account, no significant effect of hydrogen up to $3000 \mathrm{wt} . p p m$ was found at any temperature. Yamanaka et al. [64] reported that the Young's modulus between 20 and $500^{\circ} \mathrm{C}$ of pure $\alpha_{\mathrm{Zr}}$ charged in hydrogen up to 250 wt.ppm decreased with increasing hydrogen content when hydrogen is in solid solution and slightly increased when hydrogen is partially precipitated as hydrides. In the present work, the slight oxygen uptake of hydrided samples is not expected to significantly affect elastic properties 
within this concentration range [7][14]. If still uncracked at the beginning of the tensile test, oxide and $\alpha_{\mathrm{Zr}}(\mathrm{O})$ layers could be stiffer than the (prior-) $\beta_{\mathrm{Zr}}$ phase [7][14][54]. However, they are thin $(5 \sim 10 \mu \mathrm{m}$, in overall $\sim 5 \%$ of the specimen thickness) and their contribution to the measured Young's modulus is expected to be within experimental uncertainty.

Fracture-The non-hydrided model (prior-) $\beta_{\mathrm{Zr}}$ material was ductile whatever the tensile test temperature (Fig. 15 and Fig. 16), in accordance with e.g. [8] and [14]. Plastic elongation and reduction of area at fracture reached several percents at room temperature and increased with increasing temperature. The reduction of area reached $100 \%$ at $700^{\circ} \mathrm{C}$. These values of plastic elongation at fracture are consistent with those reported in [14] from tensile tests at $20 \sim 260^{\circ} \mathrm{C}$ on model non-hydrided prior- $\beta_{\mathrm{Zr}}$ sheet specimens with a gauge part of the same size as for the present specimens. As shown in Fig. 15 and Fig. 16, the model (prior-) $\beta_{\mathrm{Zr}}$ material was embrittled by hydrogen contents of 2000-3000 wt.ppm for temperatures below $500^{\circ} \mathrm{C}$. The material became macroscopically brittle at $135^{\circ} \mathrm{C}$ for an average hydrogen content of $\sim 2000$ wt.ppm and at $350 \sim 400^{\circ} \mathrm{C}$ for a content of $\sim 3000$ wt.ppm. At 20 and $135^{\circ} \mathrm{C}$, the (brittle) fracture stress of the hydrided material decreased with increasing hydrogen content within the 2000 3000 wt.ppm range (Fig. 17), down to $300 \mathrm{MPa}$ in the most brittle case (3210 wt.ppm of hydrogen, $20^{\circ} \mathrm{C}$ ).

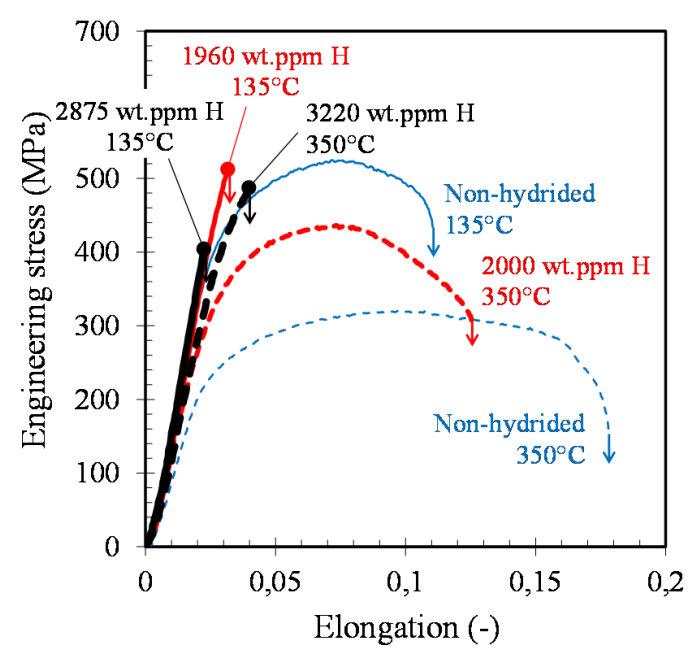

(a)

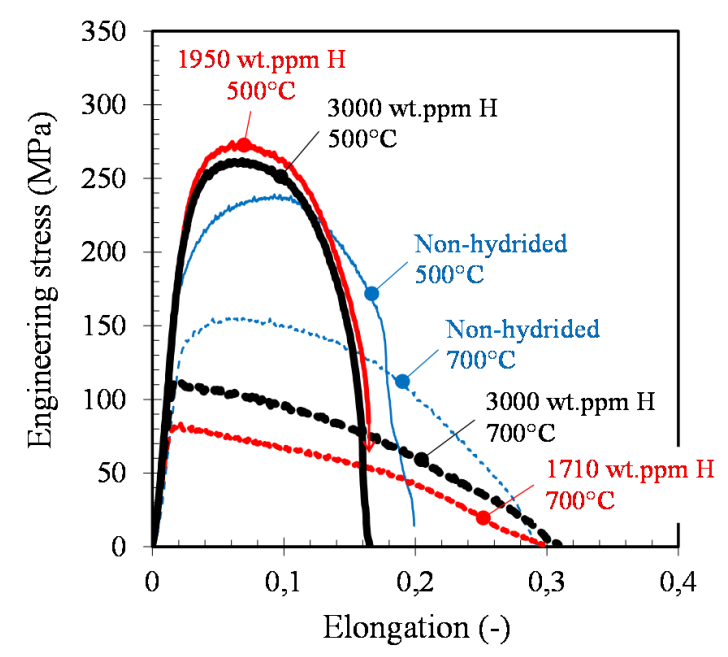

(b)

FIG. 15-Examples of engineering stress-strain (deduced from cross-head displacement) curves obtained (a) at 135 and $350^{\circ} \mathrm{C}$ and (b) at 500 and $700^{\circ} \mathrm{C}$ for model (prior-) $\beta_{\mathrm{Zr}}$ materials, with various hydrogen contents.

The effect of hydrogen on macroscopic ductility diminishes when the temperature increased (Fig. 16). It became negligible beyond $500^{\circ} \mathrm{C}$. The reduction of area at fracture was nearly $100 \%$ at 580 and $700^{\circ} \mathrm{C}$ even for the highest investigated hydrogen contents. Thus, according to these results, the macroscopic failure mode of the model (prior-) $\beta_{\mathrm{Zr}}$ material undergoes a ductile-tobrittle transition as the hydrogen content is increased and the tensile test temperature is decreased. This is illustrated in Fig. 18 where the material is considered to be brittle, nearly brittle and ductile when the plastic strain at failure is $<0.005$, between 0.005 and 0.01 and $>0.01$, respectively. This figure also includes data from the literature (their characteristics are given in Table 4). Results reported in [56] and [36] suggest that prior- $\beta_{\mathrm{Zr}}$ material may be ductile at room 
temperature even for hydrogen contents up to $3000 \mathrm{wt} . \mathrm{ppm}$. This discrepancy with the present results and with those from [3] (brittleness at $20^{\circ} \mathrm{C}, 600$ wt.ppm of hydrogen) may rely on a difference in the cooling scenario: cooling down from $800-927^{\circ} \mathrm{C}$ in air at room temperature with an initial rate of $\sim 5^{\circ} \mathrm{C} / \mathrm{s}$ in [56] and [36], cooling rate varying between $\sim 5$ and $1{ }^{\circ} \mathrm{C} / \mathrm{s}$ from $1200^{\circ} \mathrm{C}$ down to $500^{\circ} \mathrm{C}$ and slower below $500^{\circ} \mathrm{C}$ in the present case, direct water quenching from $1000^{\circ} \mathrm{C}$ in [3]. Indeed, for Zircaloy-4 pre-hydrided at $\sim 600 \mathrm{wt} . \mathrm{ppm}$ and oxidized at $1200^{\circ} \mathrm{C}$, the post-quench hardening and macroscopic ductility at room temperature strongly depend on oxygen and hydrogen partitioning during the $\beta_{\mathrm{Zr}}$ to $\alpha_{\mathrm{Zr}}$ phase transformation. Typically, increasing the cooling rate during this transformation increases the prior- $\beta_{\mathrm{Zr}}$ hardening and decreases the macroscopic ductility [58]. Furthermore, differences between the present results and those reported in [36] and [56] may also arise from the slightly higher oxygen content of the materials tested here, due to oxygen uptake during hydrogen-charging and during the heat cycle applied before tensile testing.

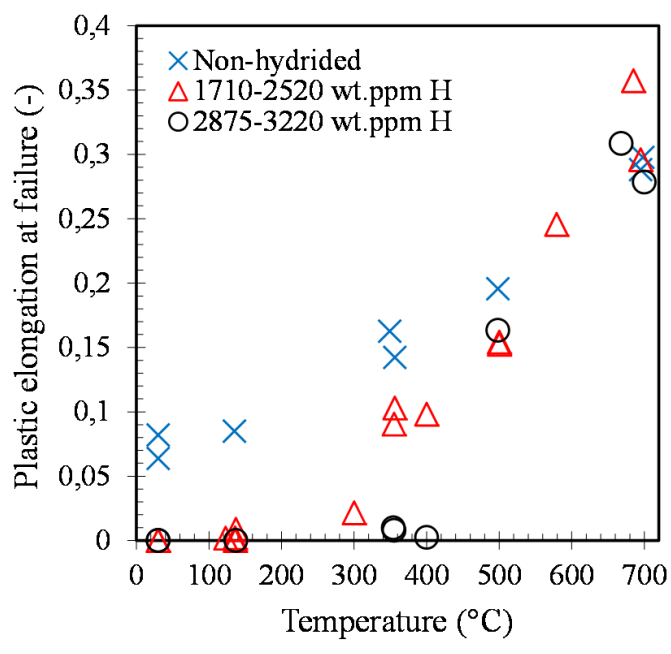

(a)

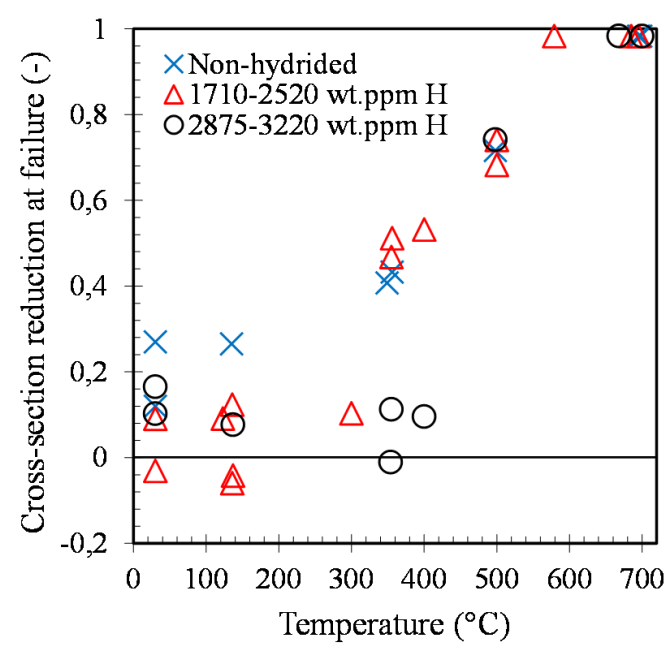

(b)

FIG. 16-Influence of temperature (a) on the plastic elongation at failure and $(b)$ on the reduction of area at fracture (accuracy of about \pm 0.08 ) obtained for model (prior-) $\beta_{\mathrm{Zr}}$ materials, as a function of hydrogen content. 


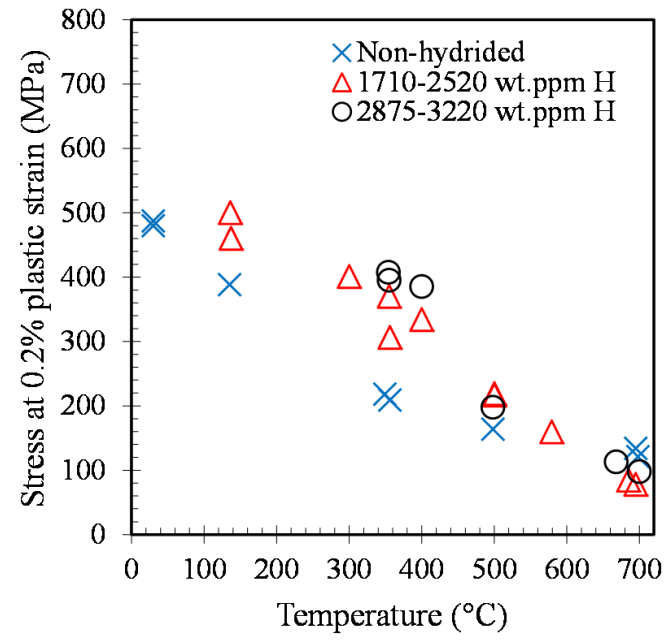

(a)

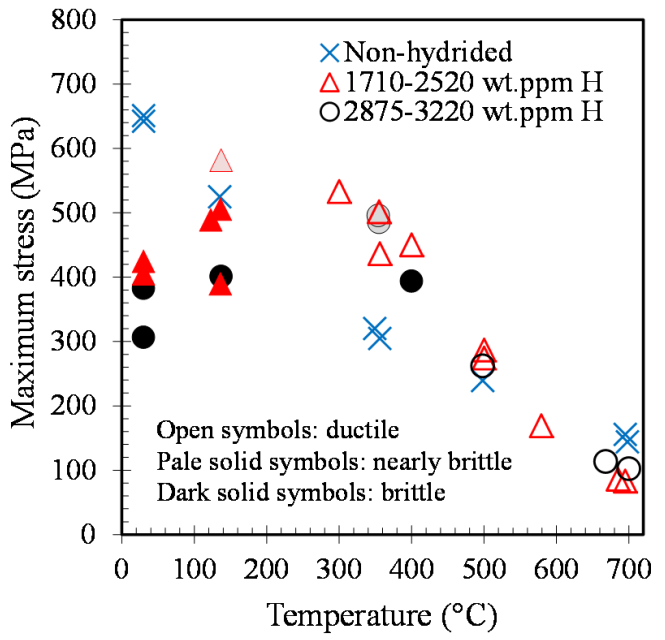

(b)

FIG. 17-Influence of temperature on (a) the $0.2 \%$ proof stress and (b) the UTS obtained for model (prior-) $\beta_{Z r}$ materials, as a function of hydrogen content.

TABLE 4-Literature data on the mechanical behavior of $\beta_{Z r}$-heat treated Zircaloy-4, pre-hydrided or not, illustrated in Fig. 18.

\begin{tabular}{|c|c|c|c|}
\hline Reference & Material & $\begin{array}{l}\text { Cooling from the } \beta_{\mathrm{Zr}} \\
\text { temperature domain }\end{array}$ & $\begin{array}{l}\text { Mechanical testing after } \\
\text { cooling }\end{array}$ \\
\hline Brachet et al. [3] & $\begin{array}{l}\text { Cladding tube, pre- } \\
\text { hydrided up to } \\
\sim 600 \text { wt.ppm or not }\end{array}$ & $\begin{array}{l}\text { Water quenching from } \\
1000^{\circ} \mathrm{C}\end{array}$ & $\begin{array}{l}\text { Impact, ring compression } \\
\text { and } 3 \text { point bending tests } \\
\text { at } 20 \text { and } 135^{\circ} \mathrm{C}\end{array}$ \\
\hline Stern et al. [14] & Sheet, non-hydrided & $\begin{array}{l}\text { Water quenching from } \\
1200 \text { or } 1300^{\circ} \mathrm{C}\end{array}$ & $\begin{array}{l}\text { Tensile tests between }-100 \\
\text { and } 260^{\circ} \mathrm{C}\end{array}$ \\
\hline Cabrera [57] & $\begin{array}{l}\text { Sheet, pre-hydrided up to } \\
\sim 600 \text { wt.ppm or not }\end{array}$ & $\begin{array}{l}\text { Water quenching from } \\
1200 \text { or } 1300^{\circ} \mathrm{C}\end{array}$ & $\begin{array}{l}\text { Tensile tests at } 20 \text { and } \\
135^{\circ} \mathrm{C}\end{array}$ \\
\hline Stuckert et al. [56] & $\begin{array}{l}\text { Cladding tube, pre- } \\
\text { hydrided up to } \\
2800 \text { wt.ppm }\end{array}$ & $\begin{array}{l}\text { Cooling down from } 800 \text { or } \\
900^{\circ} \mathrm{C} \text { in air at room } \\
\text { temperature with an initial } \\
\text { rate of } \sim 5^{\circ} \mathrm{C} / \mathrm{s}\end{array}$ & $\begin{array}{l}\text { Ring compression and } \\
\text { axial tensile tests at } 20^{\circ} \mathrm{C}\end{array}$ \\
\hline Pshenichnikov et al. [36] & $\begin{array}{l}\text { Cladding tube, pre- } \\
\text { hydrided up to } \\
10000 \text { wt.ppm }\end{array}$ & $\begin{array}{l}\text { Cooling down from } 827 \text { or } \\
927^{\circ} \mathrm{C} \text { in air at room } \\
\text { temperature with an initial } \\
\text { rate of } \sim 5^{\circ} \mathrm{C} / \mathrm{s}\end{array}$ & Axial tensile tests $20^{\circ} \mathrm{C}$ \\
\hline
\end{tabular}


FIG. 18-Ductile vs brittle fracture modes of the (prior-) $\beta_{Z r}$ phase as a function of temperature and average hydrogen content; data from this study and from [3], [14], [57], [56] and [36] (details in Table 3).

The fracture surface of brittle hydrided specimens was macroscopically perpendicular to the loading axis. After testing at 20 and $135^{\circ} \mathrm{C}$, the fracture surface of the 2000 -wt.ppm-H material appeared a little bit rougher than that of the 3000-wt.ppm-H material. This slight difference may be due to a higher volume fraction of proeutectoid $\alpha$ zr phase in the case of the lowest hydrogen content, as already discussed right after hydrogen charging. The fracture surface of ductile specimens was rough and macroscopically slanted in most cases. In the most ductile cases, above $500^{\circ} \mathrm{C}$ typically, fracture mainly occurred by through-thickness necking. Multiple cracking of the oxide layers, perpendicular to the tensile direction, was observed at the surface of the specimens that failed after significant plastic deformation. No macroscopic crack was observed at the oxide surface on the brittle specimens fractured in the elastic regime.

From SEM fractography, the thin oxide and $\alpha_{\mathrm{Zr}}(\mathrm{O})$ layers at sample surfaces broke in a brittle manner at least for temperatures up to $500^{\circ} \mathrm{C}$ (the fracture mode at $700^{\circ} \mathrm{C}$ was not clearly identified), in accordance with the above presented results on the $\alpha \mathrm{Zr}(\mathrm{O})$ material. Dimples were found on the fracture surface of the non-hydrided model (prior-) $\beta_{\mathrm{Zr}}$ material (only containing the $\alpha_{Z r}$ phase) for all temperatures between 20 and $700^{\circ} \mathrm{C}$ (Fig. 19(a)). 


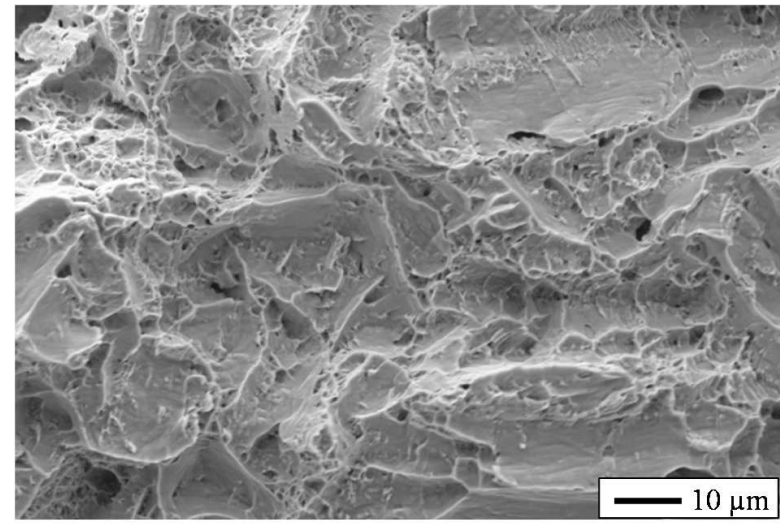

(a) non-hydrided, test at $135^{\circ} \mathrm{C}$, macroscopically ductile

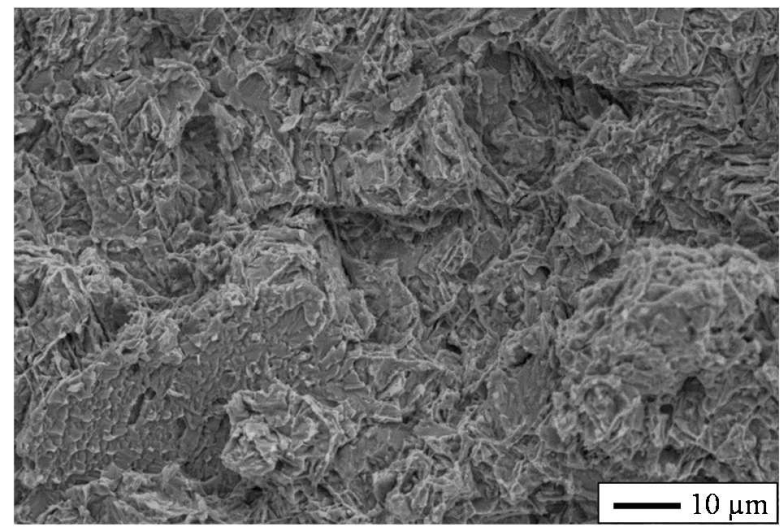

I 2875 wt.ppm of hydrogen, test at $135^{\circ} \mathrm{C}$, macroscopically brittle

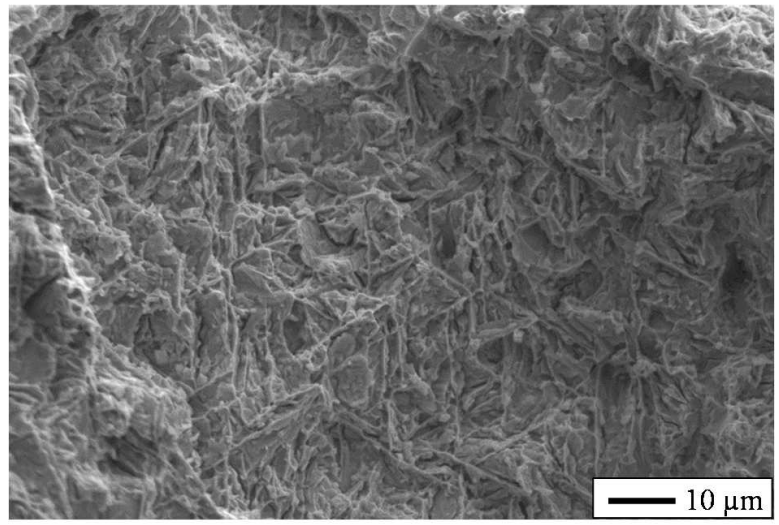

(b) 2000 wt.ppm of hydrogen, test at $135^{\circ} \mathrm{C}$, macroscopically nearly brittle

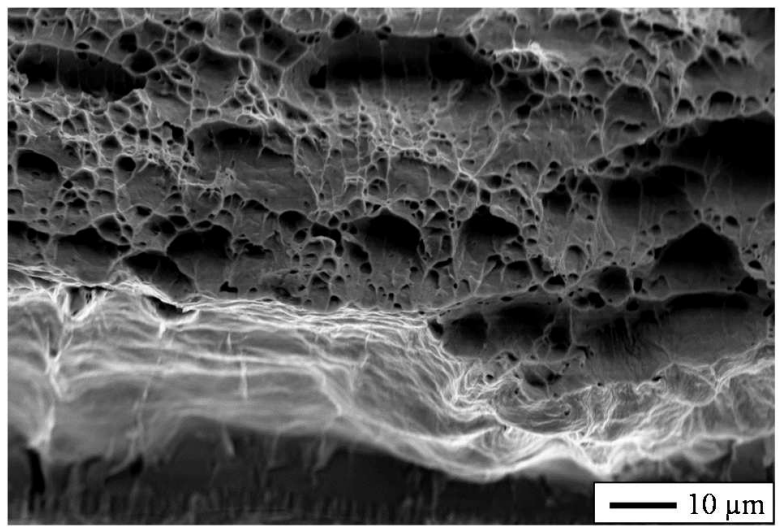

(d) 3000 wt.ppm of hydrogen, test at $500^{\circ} \mathrm{C}$, macroscopically ductile

FIG. 19-SEM fractographs of model (prior-) $\beta_{Z r}$ samples, fractured at 135 and $500^{\circ} \mathrm{C}$, with various hydrogen contents.

For testing temperatures lower than $500^{\circ} \mathrm{C}$, the material highly charged in hydrogen is a mixture of oxygen-enriched, hydrogen-depleted proeutectoid $\alpha$ zr phase and of hydrogen-enriched $\alpha \mathrm{Zr}$ formed below the eutectoid temperature. At the microscale, brittle regions were observed on the fracture surface of the macroscopically brittle hydrogen-charged materials, together with zones of ductile fracture (Fig. 19(b) and (c)). The lower the fraction of ductile zones, the highest the macroscopic brittleness. Solute element partitioning during cooling and $\beta_{\mathrm{Zr}}$ to $\alpha \mathrm{Zr}$ phase transformation depends on the mean hydrogen and oxygen contents and on the cooling scenario [58][61]. As a consequence, as already suggested in [14] for the oxygen-charged prior- $\beta_{Z \mathrm{zr}}$ phase and in [60] for the hydrogen-charged prior- $\beta_{\mathrm{Zr}}$ phase, fracture of model prior- $\beta_{\mathrm{Zr}}$ specimens containing more than $2000 \mathrm{wt}$.ppm of hydrogen in average (and slightly enriched in oxygen) initiates in a brittle manner from regions enriched in hydrogen. Final fracture mainly occurs by ductile tearing of the surrounding hydrogen-depleted regions. Even if the underlying mechanisms are not the same, this failure mode mixing brittle and ductile fracture at the microscale has similarities in appearance to the fluted fracture encountered e.g. in transgranular stress-corrosion cracking conditions [62]. These observations show that the ductile-to-brittle transition of the 
hydrogen-enriched (prior-) $\beta$ Zr phase material is not as steep at the microscale as at the macroscale, as also reported by Stern et al. [14] for oxygen-charged prior- $\beta_{\mathrm{Zr}}$ phase.

No "macroscopic" hydrides could be clearly detected by optical or scanning electron microscopy after testing. However, recent results showed that hydrogen precipitates in the form of fine intergranular $\delta$ and $\gamma$ zirconium (nano)hydrides during cooling from the $\beta_{\mathrm{Zr}}$ temperature domain and suggested that a small fraction of hydrogen should remain in solid solution within the $\alpha \mathrm{Zr}$ matrix [36][59][60]. Detailed analyses are still needed to determine the exact location, morphology and orientation of hydrides. An overview on potential hydrogen-induced embrittlement mechanisms is available from [65]. Based on [63] and [64], Pshenichnikov et al. [60] suggested that hydrogen-induced embrittlement in highly hydrogenenriched material was due to a decohesion mechanism, related to hydrogen-induced weakening of the bonds between $\mathrm{Zr}$ atoms. The mechanisms responsible for the observed hydrogen-induced embrittlement are still not clearly identified yet and require further investigation.

After testing at $500^{\circ} \mathrm{C}$, the fracture surfaces of the non-hydrided a hydrided materials appeared dimpled and similar to each other (Fig. 19(d)). For both non-hydrided and hydrogencharged specimens tested at $700^{\circ} \mathrm{C}$ (and at $580^{\circ} \mathrm{C}$ for the 2000 -wt.ppm-H material), a nearly complete reduction in thickness was observed at failure. As a result, hydrogen up to contents of $\sim 3000$ wt.ppm does not affect fracture mechanisms beyond $500^{\circ} \mathrm{C}$. At $500^{\circ} \mathrm{C}$, according to recent thermodynamic calculations and in-situ neutron diffraction experiments [59], hydrogen, for such contents, is still expected to be partially precipitated as $\delta$ hydrides. The absence of significant hydrogen-induced embrittlement at $500^{\circ} \mathrm{C}$ may be due to a lower fraction of precipitated hydrogen, a higher ductility of hydrides and/or a reduction of the potential weakening effect of hydrogen on the interatomic bonds. The materials containing 2000-3000 wt. ppm of hydrogen in average are expected to be constituted of $\beta_{\mathrm{Zr}}$ (with potentially a small fraction of proeutectoid $\left.\alpha_{\mathrm{Zr}}\right)$ at $700^{\circ} \mathrm{C}$, and of a mixture of oxygen-rich proeutectoid $\alpha_{\mathrm{Zr}}$ and of hydrogen-rich $\beta_{\mathrm{Zr}}$ at $580^{\circ} \mathrm{C}$ (the highest the hydrogen content, the lowest the fraction of proeutectoid $\alpha \mathrm{Zr}$ ). Beyond the eutectoid temperature $\left(\sim 550^{\circ} \mathrm{C}\right)$, hydrogen is fully dissolved in the $\mathrm{Zr}$ lattice and solute hydrogen seems to induce no significant embrittlement at 580 and $700^{\circ} \mathrm{C}$.

Plasticity-The $0.2 \%$ proof stress of the non-hydrided prior- $\beta \mathrm{Zr}$ material decreased with increasing temperature (Fig. 15 and Fig. 17). The limited amount of oxygen that potentially diffused into the material during the heat-treatment at HT before tensile testing probably had a slight strengthening effect [54]. The thin oxide and $\alpha_{\mathrm{Zr}}(\mathrm{O})$ layers at side surfaces could also slightly contribute to the overall mechanical response at the beginning of plastic yielding. The values of UTS are relatively close to those reported in [8] from hoop tensile tests performed at $\sim 3 \cdot 10^{-3} \mathrm{~s}^{-1}$ on non-hydrided Zircaloy- 2 cladding, $\beta \mathrm{Zr}$ heat-treated then cooled at $20^{\circ} \mathrm{C} / \mathrm{s}$ down to $850^{\circ} \mathrm{C}$, then quicker cooled down to room temperature. The values of UTS at 20 and $135^{\circ} \mathrm{C}$ were significantly lower than those reported in [14] for non-hydrided prior- $\beta_{\mathrm{Zr}}$ tensile samples produced from a Zircaloy-4 sheet, yet tested with a slower elongation rate than here. This difference could mainly be explained by the faster cooling rate applied in [14] in comparison to the present study after the incursion in the $\beta_{\mathrm{Zr}}$ temperature domain, resulting in a finer and stronger microstructure. 
Up to $500^{\circ} \mathrm{C}$, the $0.2 \%$ proof stress increased with increasing hydrogen content as long as the specimen remained macroscopically ductile (i.e. for temperatures $>135^{\circ} \mathrm{C}$ and $>350-400^{\circ} \mathrm{C}$ for mean hydrogen contents of 2000 wt.ppm and 3000 wt.ppm, respectively) (Fig. 17). This strengthening effect diminished when temperature increased. According to the model proposed in [54], the increase in oxygen content by $0.07 \mathrm{wt} . \%$ (due to the hydrogen charging step) induced, for a given plastic strain, an increase in $0.2 \%$ proof stress by only $9 \%$ for temperatures between 20 and $700^{\circ} \mathrm{C}$. Therefore, it can be considered that hydrogen has definitely a strengthening effect at $400^{\circ} \mathrm{C}$ and below. This agrees with the increase in strength and decrease in ductility reported in [36] for prior- $\beta_{Z \mathrm{Zr}}$ specimens (fabricated from Zircaloy-4) tested at room temperature when increasing the hydrogen content up to several hundreds of wt.ppm. Hydrogen also induces hardening of the prior- $\beta$ Zr phase at room temperature [3][31][36]. Strengthening of the prior- $\beta_{\mathrm{Zr}}$ phase in the presence of high hydrogen contents at $500^{\circ} \mathrm{C}$ and below can be related to the complex micro-composite microstructure of this material, i.e., a mixture of proeutectoid, oxygen-rich, hydrogen-depleted $\alpha_{\mathrm{Zr}}$ (prior- $\beta_{\mathrm{Zr}}$ ) phase, and of prior- $\beta_{\mathrm{Zr}}$ phase transformed below the eutectoid temperature, slightly depleted in oxygen but containing a very large amount of hydrogen. These hydrogen atoms are expected to be, at least partially, precipitated under the form of strengthening nano-hydrides.

At $700^{\circ} \mathrm{C}$, the material containing $1700 \sim 3000$ wt.ppm of hydrogen had a lower $0.2 \%$ proof stress than the non-hydrided material. At this temperature, all hydrogen atoms in the hydrided material were in solid solution in the zirconium matrix, expected to be mainly $\beta_{\mathrm{Zr}}$ (possibly with a small fraction of proeutectoid $\alpha_{\mathrm{Zr}}$ ), whereas the non-hydrided material was in the $\alpha_{\mathrm{Zr}}$ (prior- $\beta_{\mathrm{Zr}}$ ) phase. Hydrogen-induced softening at $700^{\circ} \mathrm{C}$ was likely due to a high volume fraction of $\beta_{\mathrm{Zr}}$, whose strength at HT is lower than that of $\alpha_{\mathrm{Zr}}$ (prior- $\beta_{\mathrm{Zr}}$ ). Hydrogen-induced decrease in $\mathrm{Zr}-\mathrm{Zr}$ bond strength [64] and enhancement of dislocation mobility [44] could also contribute to this effect to a lesser extent. A softening effect of hydrogen in solid solution, as well as a strengthening effect of hydrides, were also reported for Zircaloy- 4 in the $\alpha_{\mathrm{Zr}}$ phase tested between 20 and $480^{\circ} \mathrm{C}$ [66][67].

No significant effect of temperature or hydrogen was evidenced on average values of ratios of axial to hoop plastic strain increments measured by digital image correlation within the specimen gauge part before necking. The measured ratios are not far from -0.5 , characteristic of an isotropic plastic behavior. No significant effect of hydrogen for contents up to $1200 \mathrm{wt}$.ppm was observed either between 20 and $480^{\circ} \mathrm{C}$ for Zircaloy- 4 in the $\alpha_{\mathrm{Zr}}$ phase (yet without previous $\beta_{\mathrm{Zr}}$ heat-treatment) [67][68].

The maximum uniform elongation of the non-hydrided prior- $\beta_{\mathrm{Zr}}$ material did not evolve significantly between 20 and $135^{\circ} \mathrm{C}$, then increased with increasing temperature up to $500^{\circ} \mathrm{C}$ (Fig. 20), in accordance with the results reported in [14] for similar non-hydrided prior- $\beta_{\mathrm{Zr}}$ specimens produced from a Zircaloy-4 sheet. This evolution differs from the decreasing tendency observed for as-received Zircaloy-4, in the $\alpha_{\mathrm{Zr}}$ phase [55][67]. The uniform elongation of the non-hydrided prior- $\beta \mathrm{Zr}$ material was lower at $700^{\circ} \mathrm{C}$ than at $500^{\circ} \mathrm{C}$. Hydrided samples with 2000 wt.ppm and 3000 wt.ppm of hydrogen in average fractured without necking at temperatures lower than $350^{\circ} \mathrm{C}$ and $500^{\circ} \mathrm{C}$ respectively (Fig. 15). At higher temperatures, their uniform elongation was significantly lower than for the non-hydrided material (Fig. 20). At $700^{\circ} \mathrm{C}$, necking of the highly hydrided materials (mainly or fully in the $\beta_{\mathrm{Zr}}$ phase at this 
temperature) occurred from the very beginning of macroscopic plasticity, for a plastic strain level lower than 0.01. As long as the material can withstand significant plastic strain before failure, plastic strain localization is thus enhanced in the presence of high hydrogen contents.

FIG. 20-Effect of temperature on the maximum uniform elongation of model (prior-) $\beta_{\mathrm{Zr}}$ materials, with various hydrogen contents.

Conclusion about the effect of high hydrogen contents on the mechanical behavior of (prior-) $\beta_{Z r}$

Model materials homogeneously enriched in hydrogen at various contents between 1700 and 3200 wt. ppm were successfully prepared from Zircaloy-4 cladding tubes to investigate the effects of high hydrogen contents on the mechanical behavior of the (prior-) $\beta_{Z \text { r }}$ phase. Their tensile strength and ductility between 20 and $700^{\circ} \mathrm{C}$ are affected by high hydrogen contents in ways that strongly depend on test temperature. The results were discussed in view of the metallurgical evolutions that occur at HT and upon cooling, namely, partition of hydrogen and oxygen during decomposition of the $\beta$ zr phase and possible precipitation of hydrides in the hydrogen-rich regions of the material.

\section{Conclusions}

Oxygen and hydrogen are known to be the main chemical species responsible for embrittlement of zirconium alloys in conditions typical to a LOCA transient.

Model materials homogeneously enriched in oxygen at various contents between 2 and 5.8 wt.\% were fabricated from M5® cladding tubes to investigate the effects of high oxygen contents on the mechanical behavior of the $\alpha_{\mathrm{Zr}}(\mathrm{O})$ phase at HT. In a vacuum, the creep strength of the $\alpha \mathrm{Zr}(\mathrm{O})$ material increases with oxygen content between 800 and $1100^{\circ} \mathrm{C}$. It is significantly higher than that of the as-received material without additional oxygen. Two creep regimes were observed: a power-law regime for stresses higher than $\sim 15 \mathrm{MPa}$ and (for the first time) a nearly linear regime for lower stresses. Model $\alpha_{\mathrm{Zr}}(\mathrm{O})$ materials are ductile between 800 and $1100^{\circ} \mathrm{C}$ for oxygen contents between 2 and $3.2 \mathrm{wt} . \%$ but become brittle, even at $1100^{\circ} \mathrm{C}$, for oxygen contents higher than $4 \mathrm{wt} . \%$. Deformation and failure mechanisms, and influence of microstructure of the model oxygen-enriched $\alpha_{\mathrm{Zr}}(\mathrm{O})$ materials have been analyzed. Further 
investigations are still needed to identify the mechanisms that drive the low-stress linear creep regime. A phenomenological model was proposed to describe the influence of oxygen content on the viscoplastic flow behavior of the $\alpha_{\mathrm{Zr}}(\mathrm{O})$ phase. Finite element analysis performed by using this model for the $\alpha_{\mathrm{Zr}}(\mathrm{O})$ layer highlights the strengthening effect of this layer on the creep behavior of cladding tubes oxidized at HT while subjected to internal pressure. These data could also be of interest regarding the behavior of the oxidized cladding, which depends on the properties of each phase/layer, during the oxidation at HT and the subsequent cooling and quenching at the end of a LOCA-like transient.

The uniaxial tensile behavior of the (prior-) $\beta_{\mathrm{Zr}}$ phase highly enriched in hydrogen was investigated in air at various temperatures between 20 and $700^{\circ} \mathrm{C}$, upon cooling from the $\beta_{\mathrm{Zr}}$ temperature domain, on model (prior-) $\beta_{\text {Zr }}$ phase materials prepared from Zircaloy- 4 cladding tubes, homogeneously enriched in hydrogen up to 1700 3200 wt. ppm. The Young's modulus of the (prior-) $\beta_{Z r}$ material decreases with increasing temperature and is not much affected by hydrogen. Its ductility increases with increasing temperature. The material is embrittled by hydrogen for temperatures below $500^{\circ} \mathrm{C}$. It becomes macroscopically brittle at $135^{\circ} \mathrm{C}$ for an average hydrogen content of $\sim 2000$ wt.ppm and at $350 \sim 400^{\circ} \mathrm{C}$ for $\sim 3000$ wt.ppm of hydrogen. The effect of hydrogen on macroscopic ductility diminishes when temperature increases; it becomes negligible beyond $500^{\circ} \mathrm{C}$. As long as the behavior is macroscopically ductile, hydrogen strengthens the material at $500^{\circ} \mathrm{C}$ and below, but softens it at $700^{\circ} \mathrm{C}$. Plastic isotropy is not substantially modified by hydrogen. Plastic strain localization occurs sooner in the highly hydrided material, as long as significant plastic strain occurs before failure. The results are related to the complex microstructure of the highly hydrided (prior-) $\beta_{\mathrm{Zr}}$ phase material, resulting from partition of hydrogen and other chemical elements, phase transformations beyond and below the eutectoid temperatures, and hydride precipitation. These data could be useful to assess the mechanical response, during and after quenching at the end of a LOCA transient, of the (prior-) $\beta_{Z r}$ phase in the regions of a ballooned/burst cladding that have experienced significant secondary hydriding during HT steam oxidation. However, further work has to be done to improve understanding of the physical mechanisms responsible for the observed effects of high hydrogen contents.

The results presented in this paper were obtained on model oxygen-enriched $\alpha \mathrm{Zr}(\mathrm{O})$ phase and hydrogen-enriched (prior-) $\beta$ Zr phase materials respectively produced from M5® and Zircaloy- 4 cladding tubes. The conclusions are not necessarily directly applicable to other alloys.

\section{Acknowledgments}

The authors would like to thank D. Hamon, V. Lezaud, E. Rouesne, S. Urvoy, C. ToffolonMasclet, P. Bonnaillie, M.H. Mathon, C. Raepsaet and G. Bayon from CEA, and J. Heurtel, A. Laurent, J.D. Bartout, A. Meddour, A. Köster and J.C. Teissèdre from the Centre des Matériaux (Mines ParisTech) for their contribution to this work. The authors thank AREVA and EDF for their financial contribution to this work. AREVA is also acknowledged for material supply. 


\section{References}

[1] Sawatzky, A., Ledoux, G.A. and Jones, S., "Oxidation of zirconium during a hightemperature transient," Zirconium in the Nuclear Industry, ASTM STP 633, A. L. Lowe, Jr. and G. W. Parry, Eds., American Society for Testing and Materials, 1977, pp. 134-149.

[2] Chung, H.M., Garde, A.M. and Kassner, T.F., "Development of an Oxygen Embrittlement Criterion for Zircaloy Cladding Applicable to Loss-of-Coolant Accident Conditions in Light-Water Reactors," Zirconium in the Nuclear Industry (Fourth Conference), ASTM STP 681, American Society for Testing and Materials, 1979, pp. 600-627.

[3] Brachet, J.C., Vandenberghe-Maillot, V., Portier, L., Gilbon, D., Lesbros, A., Waeckel, N. and Mardon, J.P., "Hydrogen Content, Preoxidation, and Cooling Scenario Effects on PostQuench Microstructure and Mechanical Properties of Zircaloy-4 and M5® Alloys in LOCA Conditions," Journal of ASTM International, Vol. 5, 2008.

[4] Woo, O.T. and Tangri, K., "Transformation characteristics of rapidly heated and quenched Zircaloy-4-oxygen alloys," Journal of Nuclear Materials, Vol. 79, 1979, pp. 83-94.

[5] Leistikow, S., Schanz, G., "Oxidation Kinetics and Related Phenomena of Zircaloy-4 Fuel Cladding Exposed to High Temperature Steam and Hydrogen-Steam Mixtures under PWR Accident Conditions," Nuclear Engineering and Design, Vol. 103, 1987, pp. 65-84.

[6] Erbarcher, F.J., Neitzel, H.J., Rosinger, H.E., Schmidt, H. and Wiehr, K., "Burst Criterion of Zircaloy Fuel Claddings in a Loss-of-Coolant Accident," Zirconium in the Nuclear Industry: Fifth Conference, ASTM STP 754, D.G. Frankin, Ed., American Society for Testing and Materials, 1982, pp. 271-283.

[7] Bunnell, L.R. and Bates, J.L., Mellinger, G.B., "Some high-temperature properties of Zircaloy-oxygen alloys," Journal of Nuclear Materials, Vol. 116, 1983, pp. 219-232.

[8] Sawatzky, A., "A proposed criterion for the oxygen embrittlement of Zircaloy-4 fuel cladding," Zirconium in the Nuclear Industry (Fourth Conference), ASTM STP 681, American Society for Testing and Materials, 1979, pp. 479-496.

[9] Rizkalla, A.S., Holt, R.A., Jonas, J.J., "Effect of oxygen on the deformation of Zircaloy-2 at elevated temperatures," Zirconium in the Nuclear Industry (Fourth Conference), ASTM STP 681, American Society for Testing and Materials, 1979, pp. 497-513.

[10]Burton, B., Donaldson, A.T. and Reynolds, G.L., "Interaction of Oxidation and Creep in Zircaloy-2," Zirconium in the Nuclear Industry (Fourth Conference), ASTM STP 681, American Society for Testing and Materials, 1979, pp. 561-585.

[11] Choubey, R., Jonas, J.J., Holt, R.A. and Ells, C.E., "Flow stress of oxygen-enriched Zircaloy-2 between 1023 and 1873 K," Zirconium in the Nuclear Industry: Fifth Conference, ASTM STP 754, D.G. Frankin, Ed., American Society for Testing and Materials, 1982, pp. 350-369.

[12]Chow, C.K., Rosinger, H.E. and Bera, P.C., "Creep behaviour of oxidized Zircaloy-4 fuel sheathing," Proceedings of the Materials in Nuclear Energy Conference, Huntsville, Canada, September 29-October 2, 1982, pp. 112-116.

[13] Tseng, D. and Tangri, K., "Deformation Behavior of Duplex Zircaloy-4-Oxygen Alloys," Metallurgical Transactions A, Vol. 13A, 1982, pp. 1077-1082.

[14] Stern, A., Brachet, J.C., Maillot, V., Hamon, D., Barcelo, F., Poissonnet, S., Pineau, A., Mardon, J.P. and Lesbros, A., "Investigations of the Microstructure and Mechanical Properties of Prior- $\beta$ Structure as a Function of the Oxygen Content in Two Zirconium Alloys," Journal of ASTM International, Vol. 5, No. 4, 2009, JAI101119, pp. 71-118. 
[15]Bossis, P., Pêcheur, D., Hanifi, K., Thomazet, J. and Blat, M., "Comparison of the High Burn-up Corrosion on M5 and Low Tin Zircaloy-4," Journal of ASTM International, Vol. 3, No. 1, 2008, pp. 494-525.

[16] Mardon, J.P., Garner, G. and Hoffmann, P.B., "M5® a Breakthrough in Zr Alloy," Proceedings of the International Topical Meeting on Light Water Reactor Fuel Performance, Orlando, USA, September 26-29, 2010, pp. 577-586.

[17]Leistikow, S. and Schanz, G., "Oxidation Kinetics and Related Phenomena of Zircaloy-4 Fuel Cladding Exposed to High Temperature Steam and Hydrogen-Steam Mixtures under PWR Accident Conditions," Nuclear Engineering and Design, Vol. 103, 1987, pp. 65-84.

[18] Portier, L., Bredel, T., Brachet, J. C., Maillot, V., Mardon, J. P., and Lesbros, A., "Influence of Long Service Exposures on the Thermal-Mechanical Behaviour of Zy-4 and M5 Alloys in LOCA Conditions," Journal of ASTM International, Vol. 2, No. 2, 2005, JAI12468.

[19] Baek, J.H. and Jeong, Y.H., "Breakaway Phenomenon of Zr-Based Alloys during a HighTemperature Oxidation," Journal of Nuclear Materials, Vol. 372, 2008, pp. 152-159.

[20] Vandenberghe, V., Brachet, J.C., Le Saux, M., Gilbon, D., Mardon, J.P. and Sebbari, B., "Sensitivity to chemical composition variations and heating/oxidation mode of the breakaway oxidation in M5® cladding steam oxidized at $1000^{\circ} \mathrm{C}$ (LOCA conditions)," Proceedings of TopFuel 2012, Manchester, UK, September 2-6, 2012.

[21] Uetsuka, H., Furuta, T. and Kawasaki, S., "Failure-Bearing Capability of Oxidized Zircaloy4 Cladding under Simulated Loss-of-Coolant Condition," Journal of Nuclear Science and Technology, Vol., No. 11, 1983, pp. 941-950.

[22] Billone, M., Yan, Y., Burtseva, T. and Daum, R., "Cladding Embrittlement during Postulated Loss-of-Coolant Accidents," NUREG/CR-6967, 2008.

[23] Nagase, F. and Fuketa, T., "Behavior of Pre-hydrided Zircaloy Cladding under Simulated LOCA Conditions," Journal of Nuclear Science and Technology, Vol. 42, No. 2, 2005, pp. 209-218.

[24] Stuckert, J., Große, M., Rössger, C., Klimenkov, M., Steinbrück, M. and Walter, M., "QUENCH-LOCA program at KIT on secondary hydriding and results of the commissioning bundle test QUENCH-L0," Nuclear Engineering and Design, Vol. 225, 2013, pp. 185-201.

[25] Furuta, T. and Kawasaki, S., "Reaction behavior of zircaloy-4 in steam-hydrogen mixtures at high temperature," Journal of Nuclear Materials, Vol. 105, No. 2-3, 1982, pp. 119-131.

[26] Veshchunov, M.S. and Shestak, V.E., "Modeling of Zr alloy burst cladding internal oxidation and secondary hydriding under LOCA conditions," Journal of Nuclear Materials, Vol. 461, 2015, pp. 129-142.

[27] Große, M., Stuckert, J., Steinbrück, M. and Kaestner, A., "Secondary hydriding during LOCA - Results from the QUENCH-L0 test," Journal of Nuclear Materials, Vol. 420, No. 1-3, 2012, pp. 575-582.

[28] Raepsaet, C., Bossis, P., Hamon, D., Béchade, J.L. and Brachet, J.C., "Quantification and local distribution of hydrogen within Zircaloy-4 PWR nuclear fuel cladding tubes at the nuclear microprobe of the Pierre Süe Laboratory from $\mu$-ERDA," Nuclear Instruments and Methods in Physics Research B, Vol. 266, 2008, pp. 2424-2428.

[29] Brachet, J.C., Hamon, D. and Raepsaet, C., "Capability of EPMA and $\mu$-ERDA to quantify the micro-chemical partitioning within nuclear fuel cladding materials after a LOCA transient," presented at Workshop on LOCA, Lyon, France, May 29-30, 2012. 
[30] Nagase, F. and Fuketa, T., "Effect of Pre-Hydriding on Thermal Shock Resistance of Zircaloy-4 Cladding under Simulated Loss-of-Coolant Accident Conditions," Journal of Nuclear Science and Technology, Vol. 41, No. 7, 2004, pp. 723-730.

[31] Desquines, J., Drouan, D., Guilbert, S. and Lacote, P., "Embrittlement of pre-hydrided Zircaloy-4 by steam oxidation under simulated LOCA transients," Journal of Nuclear Materials, Vol. 469, 2016, pp. 20-31.

[32] Yueh, H.K., Comstock, R.J., B., D., Le Saux, M., Lin, Y.P., Lutz, D., Park, D.J., Perez-Fero, E. and Yan, Y., "Loss of Coolant Accident Testing Round Robin," Proceedings of the LWR Fuel Performance Meeting / TopFuel 2013, Charlotte, NC, USA, September 15-19, 2013.

[33] Le Saux, M., Brachet, J.C., Vandenberghe, V., Gilbon, D., Mardon, J.P. and Sebbari, B., "Influence of Pre-Transient Oxide on LOCA High Temperature Steam Oxidation and PostQuench Mechanical Properties of Zircaloy-4 and M5 ${ }^{\mathrm{TM}}$ cladding," Proceedings of the 2011 Water Reactor Fuel Performance Meeting, Chengdu, China, September 11-14, 2011.

[34] Mazères, B., Desgranges, C., Toffolon-Masclet, C. and Monceau, D., "Contribution to Modeling of Hydrogen Effect on Oxygen Diffusion in Zy-4 Alloy During High Temperature Steam Oxidation," Oxidation of Metals, Vol. 79, No. 1-2, 2013, pp. 121-133.

[35] Négyesi, M., Burda, J., Bláhová, O., Linhart, S. and Vrtílková, V., "The Influence of Hydrogen on Oxygen Distribution inside Zry-4 Fuel Cladding," Journal of Nuclear Materials, Vol. 416, No. 3, 2011, pp. 288-292.

[36] Pshenichnikov, A., Stuckert, J. and Walter, M., "Microstructure and mechanical properties of Zircaloy-4 cladding hydrogenated at temperatures typical for loss-of-coolant accident (LOCA) conditions," Nuclear Engineering and Design, Vol. 283, 2015, pp. 33-39.

[37] Chosson, R., Gourgues, A.F., Vandenberghe, V., Brachet, J.C. and Crépin, J., "Creep flow and fracture behavior of the oxygen-enriched alpha phase in zirconium alloys," Scripta Materialia, Vol. 117, 2016, pp. 20-23.

[38] Forgeron, T., Brachet, J.C., Barcelo, F., Castaing, A., Hivroz, J., Mardon, J.P. and Bernaudat, C., "Experiment and Modeling of Advanced Fuel Rod Cladding Behavior Under LOCA Conditions: Alpha-Beta Phase Transformation Kinetics and EDGAR Methodology," Proceedings of the 12th International Symposium on Zirconium in the Nuclear Industry, ASTM STP 1354, ASTM International, West Conshohocken, PA, 2000, pp. 256-278.

[39] Le Saux, M., Vandenberghe, V., Crébier, P., Brachet, J.C., Gilbon, D., Mardon, J.P. and Sebbari, B., "Influence of steam pressure on the high temperature oxidation and post-cooling mechanical properties of Zircaloy-4 and M5 ${ }^{\mathrm{TM}}$ cladding (LOCA conditions)," Zirconium in the Nuclear Industry: 17th International Symposium, STP 1543, ASTM International, West Conshohocken, PA, 2014, pp. 1002-1053.

[40] Kaddour, D., Frechinet, S., Gourgues, A.F., Brachet, J.C., Portier, L. and Pineau, A., "Experimental determination of creep properties of Zirconium alloys together with phase transformation," Scripta Materialia, Vol. 51, 2004, pp. 515-519.

[41] Kaddour, D., Gourgues-Lorenzon, A.F., Brachet, J.C., Portier, P. and Pineau, A., "Microstructural influence on high temperature creep flow of $\mathrm{Zr}-1 \% \mathrm{NbO}$ alloy in near- $\alpha, \alpha$ $+\beta$ ), and $\beta$ temperature ranges in a high vacuum environment," Journal of Nuclear Materials, Vol. 408, 2011, pp. 116-124.

[42] Dupin, N., Ansara, I., Servant, C., Toffolon, C., Lemaignan, C. and Brachet, J.C., "A Thermodynamic Database for Zirconium Alloys," Journal of Nuclear Materials, Vol. 275, 1999, pp. 287-295. 
[43] Toffolon, C., Guilbert, T. and Brachet, J.C., "Study of secondary intermetallic phase precipitation/dissolution in $\mathrm{Zr}$ alloys by high temperature-high sensitivity calorimetry," Journal of Nuclear Materials, Vol. 372, 2008, pp. 367-378.

[44] Chosson, R., "Creep behavior under internal pressure of zirconium alloy cladding oxidized in steam at high temperature," PhD Thesis (in French), Mines ParisTech, France, 2014.

[45] Trego, G., "High temperature creep behavior in the $(\alpha+\beta)$ phase temperature range of M5® alloy," PhD Thesis (in French), Mines ParisTech, France, 2011.

[46]Donaldson, A.T. and Evans, H.E., "Oxidation-induced creep in Zircaloy-2: II. Stress distribution in the oxygen-stabilised $\alpha$-phase layer," Journal of Nuclear Materials, Vol. 99, 1981, pp. 47-56.

[47]Coble, R.L., "A Model for Boundary Diffusion Controlled Creep in Polycrystalline Materials," Journal of Applied Physics, Vol. 34, No. 6, 1963, pp. 1679-1682.

[48] Herring, C., "Diffusional Viscosity of a Polycrystalline Solid," Journal of Applied Physics, Vol. 21, 1950, pp. 437-445.

[49] Novotný, J., Fiala, J. and Cadek, J., "Harper-Dorn creep in alpha-zirconium," Acta Metallurgica, Vol. 33, No. 5, 1985, pp. 905-911.

[50] Garde, A., Chung, H.M. and Kassner, T.F., "Uniaxial Tensile Properties of Zircaloy Containing Oxygen: summary Report," Report ANL-77-30, Argonne National Laboratory, 1977.

[51] Roddy, M.J., Cannon, W.R., Skandan, G. and Hahn, H., "Creep behavior of nanocrystalline monoclinic $\mathrm{ZrO}_{2}$," Journal of the European Ceramic Society, Vol. 22, 2002, pp. 2657-2662.

[52] Chokshi, A. H., "Diffusion, diffusion creep and grain growth characteristics of nanocrystalline and fine-grained monoclinic, tetragonal and cubic zirconia," Scripta Materialia, Vol. 48, 2003, pp. 791-796.

[53] Yoshida, M., Shinoda, Y., Akatsu T. and Wakai, F., "Superplasticity-like deformation of nanocrystalline monoclinic zirconia at elevated temperatures," Journal of the American Ceramic Society, Vol. 87, No. 6, 2004, pp. 1122-1125.

[54] Siefken, L.J., Coryell, E.W., Harvego, E.A. and Hohorst, J.K., "SCDAP/RELAP5/MOD 3.3 Code Manual: MATPRO - A Library of Materials Properties for Light-Water-Reactor Accident Analysis," NUREG/CR-6150, 2001.

[55]Le Saux, M., Besson, J., Carassou, S., Poussard, C. and Averty, X., "A model to describe the anisotropic viscoplastic mechanical behavior of fresh and irradiated Zircaloy-4 fuel claddings under RIA loading conditions," Journal of Nuclear Materials, Vol. 378, No. 1, 2008, pp. 60-69.

[56] Stuckert, J., Große, M. and Walter, M., "Mechanical properties of pre-hydrogenated (600 5000 wppm) cladding segments," Proceedings of the Quench Workshop 2010, Karlsruhe, Germany, November 16-18, 2010.

[57] Cabrera Salcedo, A., "Modeling of mechanical behavior of quenched zirconium-based nuclear fuel claddings, after a high temperature oxidation," PhD Thesis (in French), Mines ParisTech, France, 2012.

[58]Brachet, J.C., Hamon, D., Béchade, J.L., Forget, P., Toffolon-Masclet, C., Raepsaet, C., Mardon, J.P. and Sebbari, B., "Quantification of the chemical elements partitioning within pre-hydrided Zircaloy-4 after high temperature steam oxidation as a function of the final cooling scenario (LOCA conditions) and consequences on the (local) materials hardening," Proceedings of the IAEA Technical Meeting on Fuel Behaviour and Modelling Under 
Severe Transient and LOCA Conditions, IAEA-TECDOC-CD-1709, Mito-city Ibaraki-ken, Japan, October 18-21, 2011, pp. 253-265.

[59]Turque, I., Le Saux, M., Brachet, J.C., Crépin, J., André, G. and Toffolon-Masclet, C., "Metallurgical evolution of a highly hydrided zirconium alloy upon cooling from high temperature," Proceedings of the Minerals, Metals and Materials Society 2015 144th Annual Meeting \& Exhibition, Orlando, USA, March 15-19, 2015.

[60] Pshenichnikov, A., Stuckert, J., Walter, M. and Litvinov, D "Hydrides and fracture of pure zirconium and Zircaloy-4 hydrogenated at temperatures typical for loss-of-coolant accident conditions," Proceedings of the 23rd International Conference on Nuclear Engineering (ICONE-23), Chiba, Japan, May 17-21, 2015.

[61] Brachet, J.C., Toffolon-Masclet, C., Hamon, D., Guilbert, T., Trego, G., Jourdan, J., Stern, A. and Raepsaet, C., "Oxygen, Hydrogen and Main Alloying Chemical Elements Partitioning Upon Alpha-Beta Phase Transformation in Zirconium Alloys," Solid State Phenomena, Vol. 172-174, 2011, pp. 753-759.

[62] Leech, N.A. and Garlick, A., "The influence of environment on the formation of fluting microstructures during fracture of Zircaloy," Journal of Nuclear Materials, Vol. 125, 1984, pp. 19-24.

[63] Yamanaka, S., Yamada, K., Kurosaki, K., Uno, M., Takeda, K., Anada, H., Matsuda, T. and Kobayashi, S. "Analysis of the electronic structure of zirconium hydride," Journal of Alloys and Compounds, Vol. 330-332, 2002, pp. 313-317.

[64] Yamanaka, S., Setoyama, D., Muta, H., Uno, M., Kuroda, M., Takeda, K. and Matsuda, T., "Characteristics of zirconium hydrogen solid solution," Journal of Alloys and Compounds, Vol. 372, 2004, pp. 129-135.

[65] Lynch, S., "Hydrogen embrittlement phenomena and mechanisms," Corrosion Reviews, Vol. 30, No. 3-4, 2012, pp. 105-123.

[66] Rupa, N., Clavel, M., Bouffioux, P., Domain, C. and Legris, A., "About the mechanisms governing the hydrogen effect on viscoplasticity of unirradiated fully annealed Zircaloy-4 sheet," Zirconium in the Nuclear Industry: Thirteenth International Symposium, ASTM STP 1423, G.D. Moan and P. Rudling, Eds., ASTM International, West Conshohocken, PA, 2002, pp. 811-834.

[67] Le Saux, M., Besson, J., Carassou, S., Poussard, C. and Averty, X., "Behavior and failure of uniformly hydrided Zircaloy-4 fuel claddings between $25^{\circ} \mathrm{C}$ and $480^{\circ} \mathrm{C}$ under various stress states, including RIA loading conditions," Engineering Failure Analysis, Vol. 17, No. 3, 2010, pp. 683-700.

[68] Grange, M., Besson, J. and Andrieu, E., "Anisotropic behavior and rupture of hydrided Zircaloy-4 sheets," Metallurgical and Materials Transactions A, Vol. 31, 2000, pp. 679-690. 